Revista lus et Praxis, Año 19, № 2, 2013, pp. 301 - 334

ISSN 0717 - 2877

Universidad de Talca - Facultad de Ciencias Jurídicas y Sociales

"Tomando los derechos colectivos en serio: el derecho a consulta previa del

Convenio 169 de la OIT y las instituciones representativas de los pueblos indígenas"

Cristóbal Carmona Caldera

\title{
TOMANDO LOS DERECHOS COLECTIVOS EN SERIO: EL DERECHO A CONSULTA PREVIA DEL CONVENIO 169 DE LA OIT Y LAS INSTITUCIONES REPRESENTATIVAS DE LOS PUEBLOS INDÍGENAS*
}

TAKING COLLECTIVE RIGHTS SERIOUSLY:

THE RIGHT TO PRIOR CONSULTATION OF ILO CONVENTION 169

AND THE REPRESENTATIVE INSTITUTIONS OF THE INDIGENOUS PEOPLES

\section{Cristóbal Carmona Caldera*}

"Two households, both alike in dignity"

William SHAKESPEARE, The Tragedy of Romeo and Juliet

\begin{abstract}
RESUMEN
El presente trabajo se enfoca en el mandato contenido en el art. 6 del Convenio 169 de la OIT, referente a que la consulta previa a los pueblos indígenas sea realizada a través de las instituciones representativas de los pueblos indígenas. Específicamente, se aborda el problema de cómo comprender la antinomia entre derechos colectivos

y derechos individuales, cuando dichas instituciones, sea en su constitución, organización o funcionamiento, restringen determinados derechos individuales de sus miembros. Ante ello, se plantea que existen dos formas de comprender dicho

problema. La primera, que considera que los derechos individuales tienen una primacía clara sobre el derecho propio indígena; la segunda, que es la que defiende el presente artículo, estima que no existe tal claridad en la prioridad entre ambos derechos, en tanto el corpus iuris contemporáneo en materia de derechos indígenas se basa en el reconocimiento de estos pueblos como sujetos colectivos de derechos fundamentales, lo que implicaría que la correcta forma de comprensión jurídica de la antinomia mencionada es como una colisión de derechos de igual jerarquía.
\end{abstract}

ABSTRACT

The present work focuses on the legal command indicated in article 6 of ILO

Convention 169, concerning that prior consultation has to be done through the representative institutions of indigenous peoples. Specifically, it addresses the issue of how to understand the antinomy between collective and individual rights, which

* Trabajo recibido el 07 de junio y aprobado el 02 de septiembre de 2013.

** Abogado U. de Chile, Mg. en Estudios Filosóficos UAH, Mg. en Derechos Humanos y Democratización UNSAM (Argentina), Profesional externo del Programa de Antropología Jurídica e Interculturalidad, Facultad de Derecho, Universidad de Chile. Correo electrónico: c.g.carmona@gmail.com. El autor agradece a María de los Ángeles Fernández por su atenta lectura y precisos comentarios al texto. 
arises whenever these institutions, by their procedures of constitution, organization or operation, restrict certain rights of its members. In this sense, this article sets out two ways of comprehending the abovementioned issue. The first one stands that individual rights have a clear primacy upon the collective rights of the peoples; the second one, which is the one defended in this work, states that the priority between both kinds of rights is not manifest, in so far as the contemporary legal order in the matter is based on the recognition of indigenous peoples as collective subjects of fundamental rights, implying that the correct way of understanding this antinomy is as conflictive rights of equal hierarchy.

PalabRas Clave

Consulta previa, Instituciones representativas, Derechos colectivos

KEYWORDS

Prior consultation, Representative Institutions, Collective rights

A pesar de la actitud equívoca que en un comienzo tuvieron los diferentes poderes del Estado respecto de la aplicación del derecho a consulta del Convenio 169 de la OIT (Convenio), en la actualidad, en gran medida por las decisiones de la Corte Suprema desde julio del 2011 en adelante', ya no se puede discutir que este derecho es plenamente exigible, y que constituye un proceso autónomo y diverso de otras formas de participación contenidas en nuestro ordenamiento jurídico, con las que en algún momento se le intentó homologar-recuérdese la equivalencia que hizo la propia Corte Suprema entre consulta y la participación ciudadana de la Ley $N^{0} 19.300^{2}$, o la realizada por Contraloría y el Tribunal

\footnotetext{
${ }^{1}$ Ver Asociación Indígena Consejo de Pueblos Atacameños con Comisión Regional del Medio Ambiente Región Antofagasta, Corte Suprema, Recurso de Protección, 13 de julio de 2011. En: http://suprema. poderjudicial.cl/SITSUPPORWEB/DownloadFile.do?TIP_Documento=3\&TIP_Archivo=3\&COD_ Opcion $=1 \&$ COD_Corte $=1 \&$ CRR_IdTramite $=975635 \&$ CRR_IdDocumento $=602580$ [visitado el 23/03/2012]; Comunidad Indígena Antu Lafquen de Huentetique contra Comisión Regional del Medio Ambiente Región de Los Lagos, Corte Suprema, Recurso de Protección, 22 de marzo de 2012. En: http://suprema.poderjudicial.cl/SITSUPPORWEB/DownloadFile.do?TIP_Documento=3\&TIP_ Archivo=1\&COD_Opcion=1\&COD_Corte=1 \&CRR_IdTramite=1065562\&CRR_IdDocumento=662461 [visitado el 14/06/2012]; Marcelo Condore Vilca Consejero Territorial Alto Tarapacá y otros contra Directora Servicio de Evaluación Ambiental Primera Región de Tarapacá, Corte Suprema, Recurso de Protección, 30 de marzo de 2012. En: http://suprema.poderjudicial.cl/SITSUPPORWEB/ DownloadFile.do?TIP_Documento=3\&TIP_Archivo=1\&COD_Opcion $=1 \&$ COD_Corte $=1 \& C R R \_$ IdTramite=1067895\&CRR_IdDocumento=664550 [visitado el 15/07/2012]; $y$, finalmente, $y$ de gran relevancia pues era la primera vez que se invalidaba una Resolución de Calificación Ambiental de un Estudio de Impacto Ambiental, en donde además de PAC se habían realizado "mesas técnicas" con las comunidades, es Comunidad Agrícola Los Huasco Altinos con Comisión de Evaluación III Región de Atacama, Corte Suprema, Recurso de Protección, 27 de abril de 2012. En: http://suprema.poderjudicial. cl/SITSUPPORWEB/DownloadFile.do?TIP_Documento=3\&TIP_Archivo=1\&COD_Opcion=1\&COD_ Corte $=1 \&$ CRR_IdTramite $=1075418 \&$ CRR_IdDocumento=671213 [visitado el 11/05/2012] .
}

${ }^{2}$ La sentencia clásica en este sentido es Javier Nahuelpan y otros Contra Corema Región de Los Ríos, Corte Suprema, Recurso de Protección, 14 de octubre de 2010. En: http://suprema.poderjudicial.cl/ SITSUPPORWEB/DownloadFile.do?TIP_Documento=3\&TIP_Archivo=3\&COD_Opcion=1\&COD_ 
Constitucional con las formas de oposición existentes en los procedimientos de constitución de concesiones eléctricas y mineras, respectivamente ${ }^{3}-$.

Sin embargo, aun cuando se haya despejado la incertidumbre inicial respecto a su procedencia -al menos en lo que respecta al Sistema de Evaluación de Impacto Ambiental (SEIA)-, persiste un vacío normativo en relación con una regulación formal de la consulta cuyo contenido respete los estándares internacionales en la materia -el D.S. № 124/2009 de Mideplan claramente no lo hacía ${ }^{4}$, y la propuesta y normativa actuales (Propuesta del Gobierno para Nueva Normativa de Consulta y Participación y Nuevo Reglamento del SEIA), requieren severas modificaciones si quieren hacerlo ${ }^{5}-$. Junto a ello, se debe considerar aquellos problemas que surgen al momento de la aplicación de la norma -sea de la fuente primaria o de la legislación secundaria dictada para implementarla- en un contexto jurídico-político determinado, lo que ha sido escasamente tratado por la doctrina. Dado este escenario de incertidumbre, se hace necesario profundizar en el debate respecto al contenido sustantivo de los elementos que conforman el derecho a consulta, y es dentro de este objetivo general que se enmarca el presente artículo.

Específicamente quisiera abordar un problema que se da en la aplicación de este derecho, pero que, a su vez, tiene implicancias más amplias dentro del debate acerca de los derechos colectivos de los pueblos indígenas. Me refiero a cómo entender jurídicamente la antinomia entre el derecho colectivo del pueblo indígena y los derechos individuales de sus miembros, que puede ocurrir si la constitución, organización y/o funcionamiento de las "instituciones representativas" con las que se lleva a cabo el proceso consultivo, restringe

Corte=1\&CRR_IdTramite=958519\&CRR_IdDocumento=591128 [visitado el 07/08/2012]. Para una revisión de esta primera etapa, se puede consultar CONTESSE, J. y LoverA, D., "El Convenio 169 de la OIT en la jurisprudencia chilena: prólogo del incumplimiento", en Anuario de Derecho Público 2011. Editorial Universidad Diego Portales, Santiago, Chile, 2011, pp. 127-151.

${ }^{3}$ Contraloría General de la República, informa sobre recurso de protección, 17 de diciembre de 2009. En: http://www.contraloria.cl/LegisJuri/DictamenesGeneralesMunicipales.nsf/FrameSetConsultaWebA nonima?OpenFrameset [visitado el 20/11/2012] y Requerimiento presentado por un grupo de señores Diputados, que representan más de la cuarta parte de los miembros en ejercicio de la Cámara, respecto de la inconstitucionalidad del Convenio $\mathrm{N}^{\circ} 169$, Tribunal Constitucional de Chile, requerimiento por inconstitucionalidad, 4 de agosto de 2000. En: http://www.tribunalconstitucional.cl/wp/ver.php?id=310 [visitado el 01/09/2011].

${ }^{4}$ Así lo expresó la CEARC, en su solicitud directa al Estado de Chile, OIT. Solicitud Directa (CEACR) - adopted 2010, published 100th ILC session (2011). En: http://www.ilo.org/dyn/normlex/ en/f?p=1000:13100:0::NO::P13100_COMMENT_ID,P13100_LANG_CODE:2334939,es:NO [visitado el $22 / 10 / 2012]$.

${ }^{5}$ Véase HRC. Estándares del deber de consulta. Comentarios del Relator Especial a la Propuesta de Reglamento de Consulta del Gobierno de Chile, noviembre de 2012. En: http://www.politicaspublicas. net/panel/re/docs/1654-comentario-reglamento-chile.html [visitado el 13/01/13]. 
derechos individuales de sus miembros; esto, que es evidente en los casos de sociedades indígenas organizadas de manera patriarcal, sucede en cuestiones tan aparentemente alejadas como la marginación de instancias de decisión por parte de una autoridad de la comunidad, de aquellas personas que negociaron individualmente con el titular de un proyecto de inversión. Brevemente, y aun cuando sean cuestiones íntimamente relacionadas, lo que me interesa acá no es plantear una forma de solución al dilema entre derechos colectivos e individuales, sino la meta-pregunta por la estructura del problema; en otras palabras, ¿cuál es, dentro del ordenamiento jurídico actual, la forma correcta de comprensión de esta antinomia?

Así, (I) comenzaré por señalar las características de la obligación de consultar a través de las instituciones representativas de los pueblos indígenas, clarificando el rol del Estado en ella, y especificando el conflicto normativo que puede suscitarse entre el derecho colectivo de un pueblo y los derechos individuales de sus miembros. Luego (II) analizaré una primera forma de comprensión de este conflicto, en donde el derecho propio indígena ${ }^{6}$ podría ser reconocido por el Estado, sólo si respeta en forma absoluta los derechos fundamentales de sus miembros. A continuación, (III) argumentaré que dicha lectura del problema es errada, pues haría inviable el reconocimiento de la diferencia indígena, lo que es inadmisible toda vez que en la actualidad el paradigma jurídico aboga fuertemente por la protección de la misma. (IV) Terminaré con unas breves reflexiones acerca de la situación de las instituciones representativas en la Consulta Indígena del SEIA.

\section{La Obligación del Estado de CONSUltar a tRAVÉS DE LAS "INSTITUCIONES REPRESENTATIVAS" DE LOS PUEBLOS INDÍGENAS}

La norma matriz del derecho a consulta ${ }^{7}$ se encuentra en el art. 6.1, letra a) del Convenio, que establece el deber de los gobiernos de:

a) consultar a los pueblos interesados, mediante procedimientos apropiados y en particular a través de sus instituciones representativas, cada vez que se prevean medidas legislativas o administrativas susceptibles de afectarles directamente;

De los diversos elementos que integran esta definición -los que, se sabe, se encuentran complementados por las obligaciones contenidas en el artículo 6.2

\footnotetext{
"Uso el término "derecho propio" en vez de "derecho consuetudinario" en tanto aquél reafirma la idea de que la legitimidad del derecho indígena no se encuentra en su origen ancestral o prehispánico, sino en "la vigencia que siga o no teniendo el sistema como eje de organización política de las comunidades y que efectivamente constituya uno de los referentes centrales de la identidad y del sistema jurídico". Véase SIerRa, María Teresa, "Esencialismo y autonomía: paradojas de las reivindicaciones indígenas", Alteridades, año 7, № 14, 1997, p. 135.
}

${ }^{7}$ Esta denominación del art. 6 como "norma matriz" la tomo de Matías Meza-Lopehandía. 
del Convenio-, quisiera detenerme en el mandato que obliga a que la consulta sea realizada a través de las "instituciones representativas" de los pueblos indígenas. Este mandato es importante, pues deriva de la prerrogativa que se les reconoce a estos pueblos en el derecho internacional para "asumir el control de sus propias instituciones" -como expresa el párrafo $5^{\circ}$ del Preámbulo del Convenio-y "conservar y reforzar sus propias instituciones políticas, jurídicas, económicas, sociales y culturales" -como a su vez especifica el art. 5 de la Declaración sobre los Derechos de los Pueblos Indígenas (DDPI)-. Asimismo, este elemento es una pieza fundamental del actual corpus iuris en materia de pueblos indígenas, al estar estrechamente vinculado con otros derechos colectivos como el derecho a la libre determinación ${ }^{8}$, el derecho a conservar su identidad e integridad cultural ${ }^{9}$ y el derecho a la protección de su territorio ${ }^{10}$.

Considerando lo anterior, quizá una buena forma de empezar a acercarnos a nuestro problema es analizando las precisiones que han aportado los organismos internacionales al respecto. A primera vista, las directrices son claras: tanto los órganos de control de Naciones Unidas como del Sistema Interamericano de Derechos Humanos (SIDH), han establecido que deben ser los mismos pueblos afectados quienes determinen, "fruto de un proceso propio, interno"11 realizado "de conformidad a sus costumbres y tradiciones"12, las personas o grupos que estarán involucrados en la consulta ${ }^{13}$.

\footnotetext{
${ }^{8}$ Art. 3 DDPI. Sobre el desarrollo del derecho internacional de los derechos humanos y el concepto de libre determinación respecto de los pueblos indígenas, Véase ANAYA, James, Los pueblos indígenas en el derecho internacional, segunda edición, Editorial Trotta, Madrid, 2005, en especial sus capítulos 2 y 3, y Kүмцıска, Will, Multicultural Odysseys. Navigating the New International Politics of Diversity, Oxford University Press, Nueva York, 2007, pp. 27-55. Para la comprensión del derecho a la autodeterminación como un derecho humano y no vinculado substancialmente a la soberanía estatal, ver ANAYA, James, "The right of indigenous peoples to self determination in the post-declaration era", en Charters, C. y Stavenhagen, R, Making the Declaration work. The United Nations Declaration on the Rights of Indigenous Peoples. IWGIA, Copenhague, 2009, pp. 184-198.
}

${ }^{9}$ Art. 2.2, letra b), y art. 5, letras a) y b) del Convenio; art. 8 de la DDPI. Para un razonamiento en este sentido, véase Sentencia de la Corte Constitucional de Colombia, T-973/09, M.P. Mauricio González Cuervo.

${ }^{10}$ Art. 13 del Convenio; art. 25 de la DDPI. Al respecto, véase BerRAONDO, Mikel, "Tierras y territorios como elementos sustantivos del derecho humano al medio ambiente", en BerRaOndo, M. (Coord.), Pueblos Indígenas y Derechos Humanos, Universidad de Deusto, Bilbao, 2006, pp. 482 y 483.

11 OIT, Consejo de Administración, 289a reunión, Reclamación presentada en virtud del artículo 24 de la Constitución de la OIT, México, marzo de 2004, GB.289/17/3.

12 Pueblo Saramaka Vs. Surinam, Corte IDH, Interpretación de la Sentencia de Excepciones Preliminares, Fondo, Reparaciones y Costas, 12 de agosto de 2008, Párr. 15. En: http://www.tc.gob.pe/ corte_interamericana/seriec_185_esp. pdf [visitado el 17/06/2012].

13 "[...] el pueblo Saramaka debe informar al Estado quién o quiénes lo representarán en cada uno de los procesos de consulta señalados anteriormente. El Estado deberá consultar con tales representantes a fin de cumplir con lo ordenado por el Tribunal. Una vez realizada la consulta, el pueblo Saramaka dará 
Una consecuencia importante de estas prescripciones es que se produce una des-formalización del concepto de representación, en el sentido básico que no se requiere que dichas instituciones gocen de algún tipo de reconocimiento jurídico o certificación previa por parte del Estado -por ejemplo, no es necesaria personalidad jurídica vigente- y lo que se podría requerir sería un documento de "acreditación de representantes" ante la autoridad promotora de la consulta, como se hace en la legislación peruana ${ }^{14}$. Sin embargo, si se considera el hecho que en muchos países de América Latina la estructura político-representativa de estos pueblos se encuentra -valga el oxímoron-fuertemente debilitada, entonces en la práctica puede haber situaciones en que se requiera un juicio discrecional del Estado respecto a qué instituciones consultar. A modo de ilustración: si, como correctamente señalan Salgado y Gomiz, el Estado no puede abstenerse de realizar la consulta alegando defectos en la representatividad de las instituciones indígenas ${ }^{15}$, ante situaciones de inexistencia o desorganización de éstas, será el propio Estado quien, finalmente, intervenga en su determinación, sea proponiendo mecanismos de definición, o, por ejemplo, en casos impugnación judicial de ciertos representantes, derechamente decidiendo (Estado juez) cuáles serán.

Pero la participación estatal no se agota en la hipótesis anterior -inexistencia o desorganización institucional-. En una reclamación ante la OIT contra México, en donde el gobierno mexicano llevó el proceso de consulta con sólo dos organizaciones por considerarlas las más representativas del movimiento indígena, el Comité Tripartito designado por Consejo de Administración de la OIT para examinar dicha reclamación, observó que el Convenio habla de las "instituciones representativas de los pueblos indígenas" y no de las "instituciones más representativas"16, por lo que el proceso debió haberse llevado adelante con todas las instituciones indígenas representativas. Una lectura rápida de esta decisión podría llevar a pensar que ello minimiza el elemento de discrecionalidad estatal que identifiqué Supra, pero esto no es así. En efecto, mientras el Comité Tripartito siga hablando de instituciones representativas, ello supone

a conocer al Estado las decisiones tomadas al respecto, así como sus fundamentos". Pueblo Saramaka Vs. Surinam, cit. nota n. 12, párr. 19.

${ }^{14}$ Art. 10.1 del Reglamento de la Ley No 29.785, Ley del Derecho a la Consulta Previa a los Pueblos Indígenas u Originarios reconocido en el Convenio 169 de la Organización Internacional del Trabajo: "El o los pueblos indígenas participan en los procesos de consulta a través de sus representantes nombrados conforme a sus propios usos y costumbres, debiendo acreditarlos en el proceso de consulta ante la entidad promotora, alcanzando un documento formal de acreditación".

${ }^{15}$ Salgado, J. M. y Gomiz, M. M, Convenio 169 de la O.I.T. sobre Pueblos Indígenas: su aplicación en el derecho interno argentino, $2^{\text {a }}$ edición, Observatorio de Derechos Humanos de los pueblos Indígenas, Neuquén, 2010, p. 126.

${ }^{16}$ OIT, Consejo de Administración, cit. nota n. 11, Párr. 101. 
inexorablemente una dimensión material del concepto -la "representatividad"que obliga una actividad del Estado tendiente a discriminar las instituciones u organizaciones indígenas en función a dicho criterio; es por esto que el mismo Comité señaló en ese caso -reiterando lo expresado en otros procesos similares-, que si bien lo importante era que la institución representativa fuera resultado de un proceso llevado a cabo por los propios indígenas, era esencial también asegurar que la consulta sea realizada con instituciones que son "verdaderamente representativas de las comunidades afectadas" ${ }^{\prime 17}$. En suma, como ha fallado la Corte Constitucional de Colombia, "Ios gobiernos, antes de iniciar las consultas, deben identificar y verificar que las organizaciones/instituciones con las que tienen previsto tratar cumplan con estos requisitos" ${ }^{18}$. Ello, evidentemente, no es sencillo.

Piénsese en la situación que se vivió cuando la (hoy extinta) Corema ${ }^{19}$ de la Región de los Ríos, realizó la calificación ambiental del controversial proyecto "Sistema de Conducción y Descarga al mar de Efluentes Tratados de Planta Valdivia" en febrero de 2010, en el marco del conocido conflicto Celco-Mehuín ${ }^{20}$. A dicha sesión se presentaron para ser escuchadas -no "consultadas"- autoridades tradicionales, dirigentes de comunidades y organizaciones funcionales indígenas, e indígenas individualmente considerados, todos aduciendo, en mayor o menor grado, la representación del pueblo mapuche-lafkenche, y cada uno con una postura diversa respecto de la realización del proyecto. Al fin, el Estudio de Impacto Ambiental (EIA) fue calificado favorablemente, a pesar de que, estando ya en vigencia el Convenio 169 y concurriendo todos los requisitos para ello, la autoridad ambiental no realizó ningún proceso de consulta; posteriormente, ante la impugnación judicial de la Resolución de Calificación Ambiental (RCA) del proyecto, tanto la Corte de Apelaciones de Valdivia como la Corte Suprema determinaron erróneamente que la consulta no era procedente.

Visto el escenario anterior, si nos situamos en el caso de que la consulta sí hubiese sido declarada aplicable, vale preguntarse por cuáles habrían sido las organizaciones e instituciones legitimadas para ser consultadas. ¿Podrían haber participado, por ejemplo, aquellas personas, comunidades o autoridades

\footnotetext{
${ }^{17}$ OIT, Consejo de Administración, cit. nota n. 11, Parr. 101. Ver también, OIT, Consejo de Administración, $282^{a}$ reunión. Reclamación presentada en virtud del artículo 24 de la Constitución de la OIT, Ecuador, 2 de noviembre de 2001,GB.282/14/, Párr. 44.

${ }^{18}$ Edith Magnolia Bastidas Calderón, Corte Constitucional de Colombia, acción pública de inconstitucionalidad, 22 de octubre de 2002. En: http://www.corteconstitucional.gov.co/relatoria/2002/c-891-02. htm [visitado el 13/03/2011].

${ }^{19}$ Comisión Regional del Medio Ambiente.

${ }^{20}$ A modo de aclaración metodológica: la relación de los hechos se basa en la presencia del autor en dicha sesión.
} 
tradicionales que habían firmado el Convenio de Colaboración y Asistencia Recíproca con la empresa ${ }^{21}$, acuerdo que sin estar prohibido por la legislación ambiental ${ }^{22}$, evidentemente sería contrario a la buena fe que requiere el Convenio $^{23}$ ? ¿O podrían, en cambio, las comunidades - de acuerdo a sus propios procedimientos- marginar de la participación en este proceso a aquellos miembros que negociaron individualmente con el titular del proyecto? ¿Y qué pasa con aquellas autoridades tradicionales -como el lonko- que no responden en su constitución ni a principios democráticos ni de igualdad de género? ¿Puede un Estado democrático considerar como contrapartes válidas instituciones aparentemente discriminatorias con las mujeres? Todas estas son preguntas importantes y que, necesariamente, deben ser respondidas por la autoridad pública.

Pues bien, para avanzar en el planteamiento del problema, quisiese que pensáramos en un caso hipotético similar al citado de Celco-Mehuín, pero en donde el Estado ha llevado a cabo la consulta, cumpliendo, en principio, con los términos del Convenio 169. Acá, dada la complejidad (y desestructuración) comunitaria que presenta el territorio, es posible identificar, al menos, dos formas de impugnar dicho proceso en lo que a "instituciones representativas" se refiere.

La primera es sin duda la más común, y supone cuestionar el cumplimiento del supuesto de hecho de la norma: sostener que las personas o agrupaciones consultadas no son, efectivamente, las "instituciones representativas" de la comunidad o pueblo; v. gr., porque la consulta sólo se realizó con las directivas de las comunidades indígenas creadas por la Ley $N^{\circ} 19.253$, y que hubiesen negociado ya con la empresa; reclamaciones por esta causal no son extrañas en el derecho comparado ${ }^{24}$. Sin embargo, en este trabajo quisiera centrarme

\footnotetext{
${ }^{21}$ Acuerdo firmado entre la empresa y el Sindicato de Trabajadores Independientes del Mar de Mehuín un Convenio de Colaboración y Asistencia Recíproca, por medio del cual la empresa comprometía grandes sumas de dinero a cambio no sólo de no oponerse a la construcción, sino de colaborar activamente para que el proyecto se concrete.

${ }^{22} \mathrm{El}$ art. 13 bis de la Ley $\mathrm{N}^{\circ} 19.300$ modificada por la Ley $\mathrm{N}^{\circ}$ 20.417, a pesar de que en su discusión legislativa hubo propuestas para prohibir la negociación anticipada, finalmente, sólo estableció el deber del proponente de "informar a la autoridad ambiental si han establecido, antes o durante el proceso de evaluación, negociaciones con los interesados con el objeto de acordar medidas de compensación o mitigación ambiental". Véase Fernández Grossetete, María de los Ángeles, Historia sistematizada de la ley 20.417: instrumentos de gestión ambiental y otros temas, Memoria para optar al grado de Licenciatura en Ciencias Sociales y Jurídicas, Universidad de Chile, Santiago, 2013, pp. 85 y ss.

${ }^{23}$ Véase Pueblo Indígena Kichwa de Sarayaku Vs. Ecuador, Corte IDH, Sentencia de Fondo y Reparaciones, 27 de junio de 2012, párr. 185. En: http://www.corteidh.or.cr/docs/casos/articulos/seriec_245_ esp. pdf visitado el 21/07/2012].

${ }^{24}$ En el año 2009, la Corte Constitucional de Colombia acogió una acción de tutela en contra de un proyecto minero a desarrollarse en los departamentos de Antioquia y Chocó, en la que, entre otras cosas, se solicitaba se dejara sin efecto la consulta realizada por el Ministerio del Interior, precisamente por
} 
"Tomando los derechos colectivos en serio: el derecho a consulta previa del Convenio 169 de la OIT y las instituciones representativas de los pueblos indígenas"

en una segunda posible forma de impugnación. Esta es un tanto más compleja, pues no se basa en si los hechos se adecuan o no a lo prescrito por la norma, si no en si la norma, a pesar de ser derecho aplicable, termina no siendo aplicada en el caso concreto.

Imaginemos otro caso hipotético de consulta. Supongamos ahora que no hay dudas ni controversias en torno a la representación de las comunidades que fueron consultadas y que, efectivamente, éstas fueron las elegidas por la comunidad de acuerdo a sus propias costumbres y tradiciones, tal como requiere el derecho y la jurisprudencia internacional y comparada. Sin embargo, si se examina someramente la realidad chilena y latinoamericana, encontramos que en algunas oportunidades la representación en las comunidades indígenas -de acuerdo a sus costumbres y tradiciones- puede responder a criterios distintos que los de la lógica democrática ${ }^{25}$, o en base a una participación restringida en donde se excluye a ciertos grupos, como las mujeres ${ }^{26}$.

Bajo estas circunstancias, si se tiene en cuenta que para la Comisión Interamericana de Derechos Humanos (CIDH), la Declaración Americana obliga a los estados miembros a garantizar, en las decisiones que se tome en torno a las reclamaciones sobre tierras indígenas, "que todos los miembros de la comunidad estén plena y cabalmente informados de la naturaleza y las consecuencias del proceso y se les brinde una oportunidad efectiva de participar individual o colectivamente" ${ }^{\prime 27}$, y que la Corte IDH ha estimado que "el principio de igual-

\footnotetext{
haberse llevado a cabo con líderes indígenas no representativos de las comunidades afectadas por el proyecto. Álvaro Bailarín y otros, contra los Ministerios del Interior y de Justicia; de Ambiente, Vivienda y Desarrollo Territorial; de Defensa; de Protección Social; y de Minas y Energía, Corte Constitucional de Colombia, acción de tutela, 29 de octubre de 2009. En: http://www.corteconstitucional.gov.co/ relatoria/2009/t-769-09.htm [visitado el 29/03/2011].

${ }^{25}$ La elección del Lonko en la cultura mapuche se determina, entre otras formas, por pertenecer éste a un tronco familiar que tradicionalmente ha ejercido dicho cargo.

${ }^{26}$ Por ejemplo, en una comunidad de la Sierra Sur de Oaxaca, México, en razón de los usos y costumbres de la comunidad se le impidió asumir como alcaldesa a una mujer indígena a pesar de haber sido elegida por la mayoría de la población. Véase ReYEs, Francisco, "Participación indígena en los partidos políticos", en Desafíos de la participación política indígena y de las políticas públicas para los pueblos indígenas en Latinoamérica, Fundación Konrad Adenauer (KAS)/UCT, Temuco, 2011, pp. 29 y ss. (agradezco a José Aylwin por mencionarme este caso y remitirme a la versión escrita). En el caso del pueblo aymara en Chile (Véase ECheverRía Turres, Claudia, "División sexual del trabajo y matrimonio aymara contemporáneo desde una perspectiva de género", Revista de Ciencias Sociales (Universidad Arturo Prat), № 8, 1998, pp. 97-108) y en las sociedades andinas en general (Véase SCHILIING-VACAFLOR, Almut, "Democratizing Resource Governance through Prior Consultations? Lessons from Bolivia's Hydrocarbon Sector", Giga Working Papers, № 184, junary 2012), la división sexual del trabajo otorga posiciones de género diferenciadas que tienden a circunscribir a la mujer al ámbito privado o doméstico, otorgando al hombre la representación en el espacio público.
}

${ }^{27} \mathrm{CIDH}$, Mary y Carrie Dann (Estados Unidos), Informe № 75/02, Caso 11.140, 27 de diciembre de 2002, párr. 131. 
dad ante la ley, igual protección ante la ley y no discriminación, pertenece al jus cogens ${ }^{\prime 28}$, entonces, en una primera lectura, se podría detectar una contradicción entre determinadas instituciones indígenas y los derechos humanos de los miembros de estos pueblos, y, por lo mismo, alguien pudiese alegar la invalidación de una consulta por contravenir, por ejemplo, el principio de la igualdad de género.

\section{I.I. Dos formas de comprensión del problema}

Dije al comienzo que lo que me interesaba no era descifrar o resolver dicha antinomia, sino, mostrar, en mi opinión, la forma jurídicamente correcta de "pensarla" y "comprenderla". Y es que, como ha explicado César Rodríguez Garavito, los marcos regulatorios del derecho a consulta $-y$, en realidad, de toda norma jurídica- no dependen sólo de los límites y las oportunidades creadas por las normas, sino también de las interpretaciones y las estrategias de los actores que utilizan el derecho ${ }^{29}$. La precisión es importante por cuanto, ante la situación identificada en el párrafo anterior, existen dos posibles vías de comprensión del problema, que producen -cuando no en el resultado, siempre en la argumentación que lo sostiene- respuestas normativas disímiles. Por un lado, aquella para la cual no existe un conflicto entre derechos pues, en estas situaciones, los derechos humanos individuales (lex superior) tienen una primacía normativa sobre el derecho propio indígena. Después de todo, se dice, tanto el art. 8.2 del Convenio y el art. 34 de la DDPI expresan que los pueblos indígenas tienen derecho a conservar sus "instituciones propias" o "estructuras institucionales", mientras no sean incompatibles con "los derechos humanos internacionalmente reconocidos".

La otra vía, quizá menos sencilla, está vinculada con una comprensión del derecho propio indígena como "derrotable" (defeasible). Me explico.

Las normas $^{30}$, se sabe, tienen una estructura condicional que correlaciona circunstancias genéricas con soluciones normativas ${ }^{31}$, esto es, "si ocurre $A$,

${ }^{28}$ Corte IDH, Condición Jurídica y Derechos de los Migrantes Indocumentados. Opinión Consultiva OC-18/03. Serie A No 18, del 17 de septiembre de 2003.

${ }^{29}$ Rodríguez Garavito, César, Etnicidad.gov. Los recursos naturales, los pueblos indígenas y el derecho a la consulta previa en los campos sociales minados, Centro de Estudios de Derecho, Justicia y Sociedad, Dejusticia, Bogotá, 2012, p. 52.

${ }^{30}$ Acá adopto la posición de Juan Carlos Bayón respecto a que, si se acepta que los principios pueden justificar excepciones a las reglas, entonces se podría concluir que todas las normas jurídicas se vuelven derrotables. Véase BAYón, Juan Carlos, "Derrotabilidad, indeterminación del derecho y positivismo jurídico", Isonomía, № 13, octubre 2000, pp. 93 y 94. Para una opinión contraria véase UGARTE, José Luis, "Los derechos en su nueva hora: la teoría externa de los derechos fundamentales", Revista de Derecho Universidad Católica del Norte, Año 18-Nº 2, 2011, pp. 365 y ss.

${ }^{31}$ BAYÓN, "Derrotabilidad, indeterminación", cit. nota n. 30, p. 93. 
entonces $B^{\prime \prime}$; sin embargo, como señaló en alguna oportunidad Hart, los conceptos jurídicos tienen un carácter sui generis, que se manifiesta en la imposibilidad de establecer una lista de condiciones necesarias y estrictas para su aplicación ${ }^{32}$. En este sentido, mencionaba Hart, una de las formas de contestar una acusación -además de negar la ocurrencia de los hechos sobre los que se sostiene--, sería argumentando que no obstante encontrarse presentes todos los elementos que configuran el supuesto de hecho de la norma, ésta no se aplica, por existir circunstancias que llevan a tener en cuenta excepciones que hacen que la formulación inicial de la norma resulte "derrotada" ${ }^{33}$.

Ahora bien, esto no se trata de que una norma tenga excepciones explícitas y previamente reconocidas ${ }^{34}$, porque en dicho caso la norma no se aplica simplemente porque no es aplicable. Al contrario, cuando hablamos de "derrotabilidad" de una norma, nos referimos a excepciones implícitas a ésta que aparecen al momento de su aplicación, de manera que -y esto es lo importante- la norma no se aplica aun cuando era aplicable ${ }^{35}$ : "si, de acuerdo a su significado, la regla (legal) no contiene una excepción para el caso concreto, pero estamos sin embargo (legalmente) justificados para no seguirla, entonces podemos decir que la regla es derrotada", explica Atria ${ }^{36}$.

De acuerdo a esta comprensión, entonces, en la impugnación de un proceso de consulta por haberse llevado a efecto con una institución representativa cuya configuración no respeta estándares de igualdad de género, los derechos individuales funcionarían acá como excepciones implícitas a la norma que regula la consulta: aun cuando el supuesto de hecho se cumplió, la norma puede ser "derrotada" si el cumplimiento de ese supuesto trae como consecuencia la vulneración de un bien que, en un caso determinado, la autoridad pública estima con mayor necesidad de protección. Esto significa considerar que el caso enunciado opera como una colisión de derechos en donde no está claramente

\footnotetext{
32 "This means that all legal rules and concepts are 'open'; and when an unenvisaged case arises we must make a fresh choice, and in doing so elaborate our legal concepts, adapting them to socially desirable ends". HART, H.L.A., "Jhering's Heaven of Concepts and Modern Analytical Jurisprudence", en Essays in Jurisprudence and Philosophy. Clarendon Press, Oxford, 1983, p. 270.

${ }^{33}$ HART, H. L. A. "The ascription of responsibility and rights", en Flew, A. (Ed.), Logic and Language, Basil Blackwell, Oxford, 1951, pp. 147 y 148.

${ }^{34}$ AtriA, Fernando, On Law and Legal Reasoning, Hart Publishing, Londres, 2002, pp. 137 y 138. Después de todo, como dice el mismo Hart en The concept of law, "una regla que concluye con la expresión 'a menos que...' sigue siendo una regla", por lo que en dicho caso la norma no se aplica porque no es aplicable. HART, H. L. A., The Concept of law, Segunda edición, Oxford University Press, Oxford, 1997, p. 139.

${ }^{35}$ AtriA, On Law, cita nota n. 34, p. 123. Esta y las demás traducciones del inglés presentes en el artículo son mías.

${ }^{36}$ AtriA, On Law, cita nota n. 34, p. 125.
} 
definida una jerarquía interna que dirima ex-ante dicho conflicto, sino que esto debe ser decidido al momento de la aplicación del derecho a través de un juicio discrecional.

Veamos, entonces, la primera de las posiciones hermenéuticas descritas.

\section{II. "Filtrar y enMarcar": los derechos humanos COMO MARCO DE EXPRESIÓN DEL DERECHO PROPIO INDÍGENA}

Reformulemos el problema en una pregunta concreta: ipuede la autoridad pública admitir como contrapartes instituciones indígenas que se organizan siguiendo patrones no democráticos o excluyendo a determinados miembros en función de su género o, incluso, a manera de sanción?

La primera posición hermenéutica descrita, que suele identificarse con el multiculturalismo liberal, diría que no. Como ha señalado críticamente Moreira, el multiculturalismo se estructura de manera tal que, por más que reconozca la necesidad de otorgar a los pueblos indígenas derechos diferenciados en función del grupo, la amplitud y el minucioso detalle de los derechos reconocidos se debilita al momento de tratar el derecho de estos pueblos a conservar su sistema jurídico propio, supeditando su existencia legal a la compatibilidad que tengan con los derechos humanos -sobrentendiendo por estos a los derechos individuales ${ }^{37}$-. Empero, lo que caracteriza a esta posición no es tanto este límite formal -el que ciertamente es jurídicamente ineludible como punto de partida-, sino el rigor formalista con el que se comprende y aplica, entendiéndose a los derechos fundamentales individuales como reglas conclusivas, en donde el nexo entre el hecho concreto -consulta a través de una autoridad indígena de carácter patriarcal-y la conclusión jurídica -invalidez de la consulta por basarse en una institución que discrimina en función del género- se vuelve automático. Con ello, en realidad, la pregunta inicial se reordena imperativamente en la frase "las autoridades representativas indígenas solo pueden ser reconocidas por la autoridad pública en tanto en su estructura y funcionamiento se respeten los derechos individuales de sus miembros".

La razón es sencilla, como explica Kymlicka ${ }^{38}$. Al mismo tiempo que el derecho internacional de los derechos humanos crea el espacio político para que los grupos etnoculturales puedan impugnar jerarquías heredadas, también restringe el espacio semántico de dicha impugnación, al requerir que estos

\footnotetext{
${ }^{37}$ Moreira, Manuel, "Los desafíos del 'pluralismo jurídico': sistema plurilegal o interlegalidad", Antropología y Derecho, Año 5, No 8, 2011, p. 52. Véase art. 34 DDPI.

${ }^{38}$ Es importante notar que en su obra temprana, Kymlicka sostuvo una posición bastante flexible en lo relativo a la tolerancia y los límites de una sociedad liberal para con sus minorías culturales. Véase Kymlicka, Will, Multicultural Citizenship. A liberal theory of minority rights, Oxford University Press, Oxford, 1996, pp. 165 y ss.
} 
grupos planteen sus demandas en un lenguaje específico, "concretamente, el lenguaje de los derechos humanos, de los derechos civiles liberales y del constitucionalismo democrático, con sus garantías de igualdad de género, libertad religiosa, no discriminación racial, derechos de homosexuales, debido proceso, etc." ${ }^{\prime 39}$. Tampoco habría un espacio legal en el constitucionalismo liberal para que las minorías ignoren las normas de derechos humanos en el nombre del multiculturalismo: "desde un punto de vista legal, las políticas públicas del multiculturalismo operan dentro del marco mayor del constitucionalismo liberal, y por lo tanto, todo poder otorgado a instituciones autónomas de estas minorías está sujeto a los mismos estándares de respeto por los derechos humanos y las libertades civiles, que cualquier otra institución pública" ${ }^{\prime 4}$. Así, lo que finalmente se busca "no es suprimir estas demandas diferenciadas, sino filtrarlas y enmarcarlas (to filter and frame them) a través del lenguaje de los derechos humanos, las libertades civiles y el control democrático" ${ }^{\prime 41}$.

Dentro de este paradigma, una situación interesante es la posición de James Anaya, profesor de derecho de la Universidad de Arizona y actual Relator Especial de Naciones Unidas sobre los derechos de los pueblos indígenas. Cuando en su clásico libro Los pueblos indígenas en el derecho internacional Anaya desarrolla el derecho a la "integridad cultural" como elemento de la autodeterminación de los pueblos indígenas, expone-de manera similar a Kymlicka-que el que dicha norma esté reconocida y encuentre su fundamento en el derecho internacional de los derechos humanos, implica "que el ejercicio de la cultura se ve limitado por este propio marco de los derechos humanos" y que, por tanto, algunas prácticas culturales como la discriminación a las mujeres "quedan fuera del ámbito de protección de la norma" ${ }^{42}$. Hasta ese punto, no difiere mucho de Kymlicka; sin embargo, da al menos un espacio de interpretación -el nexo entre el hecho y la consecuencia jurídica no sería automático-, pues considera que al momento de analizar si una práctica cultural está protegida o no por los derechos humanos, se le debe conceder un cierto margen al grupo cultural afectado "para que aplique sus propios procesos de interpretación y toma de decisiones en relación a las normas universales de derecho humanos, al igual que se les concede a los propios estados" ${ }^{\prime 43}$.

\footnotetext{
${ }^{39}$ Kymlicka, Will, Multicultural Odysseys, cit. nota n. 8, p. 92.

${ }^{40}$ Kymıicka, Will, Multicultural Odysseys, cit. nota n. 8, p. 93. Ver también KymlıckA, Will, "Testing the bounds of liberal multiculturalism", Ponencia presentada en la conferencia "Muslim women's equality rights in the justice system: gender, religion and pluralism", abril 2005. En: http://www.trudeaufoundation.ca/resource/public/communiq/2006coll [visitado el 16/06/2012].

${ }^{41}$ Kymlicka, Multicultural Odysseys, cit. nota n. 8, p. 96. El énfasis es mío.

${ }^{42}$ AnAYA, Los pueblos indígenas, cit. nota n. 8, p. 184. El énfasis es mío.

${ }^{43}$ ANAYA, Los pueblos indígenas, cit. nota n. 8, p. 184.
} 
Lamentablemente, Anaya no termina de desarrollar a qué se refiere con esto. Al momento de examinar asuntos relacionados con la integridad cultural, no menciona aquellos casos de diferencia cultural radical donde se vulnerarían normas de derechos humanos, centrándose únicamente en demandas benignas como la utilización de lenguas indígenas en los tribunales o la protección de sus lugares sagrados ${ }^{44}$. De igual manera, no deja de ser sorprendente que al tratar el tema del "autogobierno" de los pueblos indígenas, que para Anaya se deriva directamente de las "nociones de democracia (...) y de integridad cultural"45, ni siquiera mencione las contradicciones que pueden haber entre instituciones tradicionales y el concepto de democracia.

Con esto, se puede intuir que aquel espacio para la "interpretación cultural de los derechos humanos" que supone Anaya no es muy amplio, remitiéndose esencialmente a aquellas demandas de integridad cultural de baja intensidad, y que de ninguna manera puede comprender temas como la igualdad de género $o$ la lógica democrática; en el mejor de los casos, la "interpretación" de Anaya se reduce a verificar si es que la práctica que se alega como contraria a los derechos humanos no es sino, simplemente, una forma diversa de implementación. Con esto, no hay un verdadero espacio para la manifestación de prácticas contrarias a los derechos individuales. Dicha conclusión, por lo demás, es la que finalmente expone -quizá presionado por los marcos institucionales del lugar de enunciación de su discurso- en sus informes como Relator Especial de Naciones Unidas. En efecto, al momento de referirse a las instituciones representativas indígenas en los procesos de consulta, ha instado a que éstas funcionen respetando la prescripción universal de "eliminación de todas las formas de discriminación y violencia contra los niños y las mujeres indígenas" ${ }^{\prime 46}$, señalando, asimismo, que los criterios mínimos de representatividad deben establecerse en virtud de "los principios de proporcionalidad y no discriminación, [y, en consecuencia] deben responder a una pluralidad de perspectivas identitarias, geográficas y de género ${ }^{\prime \prime 4}$.

\footnotetext{
${ }^{44}$ Anara, Los pueblos indígenas, cit. nota n. 8, pp. 195 y ss. Como critica Kymlicka: "Pocas personas se mostrarían en desacuerdo con un principio de 'integridad cultural', si éste se limitara a aquellos casos benignos (...) Las actitudes de las personas respecto de la integridad cultural dependerán mucho de si esa norma proporciona o no una justificación para el mantenimiento de tradiciones opresivas". KYMLICKA, Will, "Teoría de los derechos indígenas", en La política vernácula. Nacionalismo, multiculturalismo y ciudadanía, Paidós, Barcelona, 2003, pp. 182.

${ }^{45}$ Anara, Los pueblos indígenas, cit. nota n. 8, pp. 224 y ss.

${ }^{46} \mathrm{HRC}$, Informe del Relator Especial sobre la situación de los derechos humanos y las libertades fundamentales de los indígenas, James Anaya, 5 de octubre de 2009, A/HRC/12/34, párr. 52.

${ }^{47}$ Relator Especial de las Naciones Unidas sobre la situación de los derechos humanos y las libertades fundamentales de los indígenas, James Anaya, Principios internacionales aplicables a la consulta en relación con la reforma constitucional en materia de derechos de los pueblos indígenas en Chile, 24 de
} 
Tanto en Kymlicka como -de manera más matizada- en Anaya, los derechos humanos individuales aparecen como excepciones introducidas explícitamente por el legislador, por lo que una reconstrucción correcta del sistema jurídico entiende que existe entre los dos derechos - derecho propio indígena y derechos individuales- una relación de prioridad determinada ${ }^{48}$, en donde los derechos fundamentales de carácter individual operan como norma de clausura de las tradiciones indígenas; sostener lo contrario -i.e., que en el ordenamiento jurídico chileno, latinoamericano o internacional, no existe una relación de prioridad entre ambos derechos-, se diría, es simplemente hacer un juicio normativo basado en información errónea o incompleta sobre el sistema. En otras palabras, por más que el art. 6 del Convenio mandate la consulta a través de las instituciones representativas, una lectura correcta del ordenamiento jurídico revela que éstas sólo son válidas en cuanto respeten los derechos individuales de sus miembros.

La jurisprudencia chilena no ha sido ajena a esta comprensión. En un fallo reciente sobre derecho al territorio indígena -autoridades tradicionales mapuche del sector Maihue-Carimallin solicitaban protección y acceso a un sitio ceremonial que se hallaba en tierra de propiedad de un particular no indígena-, la Corte Suprema adopta una actitud hermenéutica similar.

El 4 de mayo de 2012, la Corte de Apelaciones de Valdivia había acogido el recurso de protección presentado por las mencionadas autoridades, resolviendo que la tala ilegal de árboles en el complejo religioso y ceremonial mapuche huilliche Ngen Mapu Kintuante, vulneraba la garantía constitucional del ejercicio libre de todos los cultos (art. $19 \mathrm{~N}^{\circ}$ 6) y las normas del Convenio 169 referentes a la protección de la integridad cultural de los pueblos indígenas y de la relación especial de estos pueblos con la tierra o el territorio (arts. 2.1, 2.2.b, 4.1, 5.a, 13); en consecuencia, ordena el cese de la tala ilegal de árboles del

abril de 2009, párr. 31. Se podría sostener que en su último informe al HRC, Anaya estaría atenuando su posición al establecer que: "Si bien se debe alentar a los pueblos indígenas a introducir un equilibrio de género adecuado en sus instituciones representativas y de toma de decisiones, ese equilibrio de género no debe ser dictado o impuesto a los pueblos indígenas por los Estados o las empresas, como tampoco los pueblos indígenas deben imponer el equilibrio de género a ninguno de ellos". No obstante, acá el juicio de Anaya no cambia, en tanto no se niega la primacía normativa del equilibrio de género y, contrario sensu, no se reconoce un derecho de las comunidades a mantener otra forma de relaciones de género. HRC, Informe del Relator Especial sobre la situación de los derechos humanos y las libertades fundamentales de los indígenas, James Anaya. Las industrias extractivas y los pueblos indígenas, 1 de julio de 2013, A/HRC/24/41, párr. 70.

${ }^{48} \mathrm{Si}$, como señalan Rodríguez y Sucar, la interpretación es un proceso, entonces el significado atribuido en principio a una formulación normativa puede resultar revisado incorporando excepciones inicialmente no contempladas, en la medida en que se avanza en la interpretación de otros enunciados del sistema. Rodríguez, J. y SuCAR, G, "Las trampas de la derrotabilidad. Niveles de análisis de la indeterminación del derecho", en Analisi e Diritto, 1998, p. 286. 
complejo y permite el libre acceso a éste para la realización sus ceremonias; claramente, ambos mandatos constituían una limitación al derecho de propiedad del recurrido. La Corte Suprema, en cambio, revoca la sentencia, entendiendo que si bien "el ejercicio religioso que se pretende por parte de los recurrentes se encuentra garantizado en la Constitución y el instrumento internacional denominado Convenio 169 (...) al mismo tiempo encuentra sus límites en las mismas [normas]" ${ }^{\prime 49}$. Por ello, dado que el sitio en donde se ubicaba el complejo ceremonial no se encontraba en un terreno inscrito como tierra indígena según lo determina el art. 12 de la Ley $\mathrm{N}^{\circ} 19.253$, sino en el terreno de un particular no indígena, la Corte -ignorando incluso su propia jurisprudencia en materia de territorio ${ }^{50}$ - estima que:

UNDÉCIMO [...] el acto realizado por los recurrentes [autoridades mapuche] consistente en una ocupación del terreno de propiedad del recurrido [particular no indígena] importa y constituye una acción ilegal de autotutela pues a través de una vía de hecho se altera y lesiona una situación preexistente sin que exista habilitación legal o judicial para ello, debiendo en consecuencia ser calificada como arbitraria y atentatoria de la garantía cautelada en el artículo 19 № $24^{\circ}$ de la Constitución Política de la República [derecho de propiedad].

En este caso, la primacía que, según la Corte, tendría el derecho de propiedad individual sobre el derecho a la libertad de culto del pueblo mapuche, trae como resultado que la utilización tradicional de un espacio sagrado que hacen las comunidades, al vulnerar un derecho individual, sea leída mecánicamente como un acto ilegal, y no como el ejercicio de un derecho. De esta forma, el derecho que tienen los pueblos indígenas a que se les respete sus prácticas y tradiciones, así como la relación especial con su territorio, solo podría ejercerse

\footnotetext{
${ }^{49}$ Millaray Huichalaf Pradines y otros contra Juan H. Ortiz Ortiz, Corte Suprema, Recurso de Protección, 21 de septiembre de 2012. En: http://suprema.poderjudicial.cl/SITSUPPORWEB/DownloadFile.do?TIP_ Documento $=3 \&$ TIP_Archivo=1 \&COD_Opcion $=1 \&$ COD_Corte $=1 \&$ CRR_IdTramite $=1120556 \& C R R \_$ IdDocumento=711706 [visitado el 03/10/2012].

50 Véase Alejandro Papic Domínguez con Comunidad Indígena Aymara Chuzmiza y Usmagama, Corte Suprema, regularización derechos de aprovechamiento de agua, 25 de noviembre de 2009. En: http://suprema.poderjudicial.cl/SITSUPPORWEB/DownloadFile.do?TIP_Documento=3\&TIP_ Archivo=3\&COD_Opcion=1 \&COD_Corte=1\&CRR_IdTramite=517143\&CRR_IdDocumento=300721 [visitado el 15/04/2010] y Linconao Huircapan Francisca contra Sociedad Palermo Ltda., Corte Suprema, recurso de protección, 30 de noviembre de 2009. En: http://suprema.poderjudicial.cl/SITSUPPORWEB/ DownloadFile.do?TIP_Documento=3\&TIP_Archivo=3\&COD_Opcion $=1 \&$ COD_Corte $=1 \& C R R$ IdTramite $=647053 \& C R R \_I d D o c u m e n t o=385747$ [visitado el 06/12/2011]. Véase CONTESSE, Jorge, "EI derecho de consulta previa en el Convenio 169 de la OIT. Notas para su implementación en Chile", en CONTESSE, Jorge (Ed.), El Convenio 169 de la OIT y el derecho chileno, Mecanismos y obstáculos para su implementación, Ediciones UDP, Santiago, 2012, pp. 209 y ss.; y Faúndes PeÑafiel, Juan Jorge, "Primera sentencia que aplica el convenio $N^{\circ} 169$ de la OIT en Chile. Derecho a vivir en un medio ambiente libre de contaminación comprende el concepto de territorio, hábitat y protección de la cultura de los pueblos indígenas", Revista Chilena de Derecho y Ciencia Política, vol. 1 №1, 2010, pp. 97-113.
} 
"Tomando los derechos colectivos en serio: el derecho a consulta previa del Convenio 169 de la OIT y las instituciones representativas de los pueblos indígenas"

en los espacios residuales que existen más allá del "coto vedado" de los derechos fundamentales de carácter individual.

\section{LOS PUEBLOS INDÍGENAS COMO \\ SUJETOS COLECTIVOS DE DERECHOS FUNDAMENTALES}

La lectura anterior, estimo, no puede ser considerada admisible, básicamente por dos razones. Éstas, si bien se diferencian analíticamente para su mejor comprensión, en realidad representan un continuum que se relaciona de manera central con la imposibilidad de sostener -dentro del sistema jurídico contemporáneo- relaciones de prioridad claras entre ambos derechos -lo que, a su vez, justifica la comprensión del derecho propio indígena como "derrotable"-.

El primer argumento es de texto. Como se sabe, el artículo paradigmático para fundar la jerarquía de los derechos humanos individuales sobre el derecho propio indígena, es el 8.2 del Convenio, que dispone:

Dichos pueblos deberán tener el derecho de conservar sus costumbres e instituciones propias, siempre que éstas no sean incompatibles con los derechos fundamentales definidos por el sistema jurídico nacional ni con los derechos humanos internacionalmente reconocidos. Siempre que sea necesario, deberán establecerse procedimientos para solucionar los conflictos que puedan surgir en la aplicación de este principio.

Detengámonos en la última frase de la norma. Una primera cuestión a subrayar acá es que, al instituir la obligación de "establecer" procedimientos para resolver los conflictos entre costumbres e instituciones indígenas y derechos humanos, de partida se excluye la interpretación restrictiva-como reglas conclusivas o "cartas de triunfo"- de los derechos humanos en el contexto indígena.

Por otro lado, ya que no se puede excluir la posibilidad de que la "solución" a estos conflictos sea que una institución indígena pueda conservarse a pesar de ser incompatible con los derechos humanos ${ }^{51}$, entonces el principio que sostiene a la institución indígena debe tener una jerarquía normativa capaz de "derrotar" al derecho individual -después de todo, como decía Atria, "las expectativas cuando son normativas sólo pueden ser derrotadas por expectativas normativamente reconocidas" ${ }^{\prime 52}-$.

Sin embargo, existen otras normas, como los arts. 34 y 46.1 de la Declaración, que de igual forma establecen como límite o marco de la autodeterminación indígena a los derechos humanos, pero sin el matiz recién revisado.

\footnotetext{
${ }^{51}$ Si se pudiese excluir esta solución, significaría que siempre "triunfarían" los derechos humanos sobre el derecho indígena, por lo que no habría necesidad de establecer estos "procedimientos" especiales, perdiendo sentido la norma.

${ }^{52}$ AtrIA, Fernando, "Ubi ius, ibi remedium? La relevancia jurídica de los derechos humanos", Revista de Estudios de la Justicia, No 3, 2003, p. 39.
} 
La pregunta que subsiste y debe ser atendida, entonces, es cómo sostener la aserción de que no existe una relación de jerarquía absoluta entre ambos derechos, frente un articulado que explícitamente pareciese manifestar lo contrario. El razonamiento usado por la Corte Constitucional de Colombia en la clásica sentencia T-349 de 1996, en donde debía pronunciase sobre una acción de tutela interpuesta en contra de una decisión jurisdiccional de autoridades indígenas de la comunidad embera-chamí, resulta señero para comenzar a responder dicha interrogante.

La Corte Constitucional parte de la constatación de que, si bien el principio de la protección de la diversidad cultural está establecido específicamente en una norma constitucional (art. 7), éste en realidad recorre transversalmente toda la carta fundamental colombiana (arts. 10, 70, 171, 176, 246 y 286), y que, considerando que sólo con un alto grado de autonomía es posible la supervivencia cultural que prescribe la norma, concluye que el intérprete de este precepto siempre debe buscar "la maximización de la autonomía de las comunidades indígenas y, por lo tanto, [...] la minimización de las restricciones a las indispensables para salvaguardar intereses de superior jerarquía" ${ }^{53}$. De esta forma, al momento de tener que aplicar la norma del art. 246 de la Constitución-que garantiza las facultades jurisdiccionales de las autoridades indígenas a través de sus normas y procedimientos, "siempre que no sean contrarios a la Constitución y leyes de la república" ${ }^{\prime \prime 4}-$, la Corte señala:

[...] si bien la Constitución se refiere de manera general a "la Constitución y la ley" como parámetros de restricción, resulta claro que no puede tratarse de todas las normas constitucionales y legales; de lo contrario, el reconocimiento a la diversidad cultural no tendría más que un significado retórico. La determinación del texto constitucional tendrá que consultar entonces el principio de maximización de la autonomía que se había explicado anteriormente.

Por ello, al tratarse de un tema de relaciones internas de la comunidad, de cuya regulación depende en gran parte la subsistencia de la identidad cultural y la cohesión del grupo, y guiada por el principio constitucional de la "maximización de la autonomía", la Corte establece que los límites a la jurisdicción especial indígena deben ser "los mínimos aceptables", cuyo núcleo incluiría solamente el derecho a la vida, la prohibición de la esclavitud, la prohibición de la tortura, y la legalidad de los procedimientos, los delitos y las penas; a partir de ello la Corte Constitucional ha considerado constitucionalmente ad-

\footnotetext{
${ }^{53}$ Ovidio González Wasorna con Asamblea General de Cabildos Indígenas región Chamí y Cabildo Mayor Único (CRIR), Corte Constitucional de Colombia, acción de tutela, 8 de agosto de 1996. En: http://www.corteconstitucional.gov.co/relatoria/1996/T-349-96.htm [visitado el 23/12/2011].

${ }^{54}$ En Chile, art. 54 de la Ley $N^{0} 19.253$ consagra límites similares.
} 
misibles una serie de restricciones a las libertades individuales de miembros de comunidades ${ }^{55}$.

De manera similar, en el ámbito internacional, si se considera la evolución que ha experimentado el derecho de los pueblos indígenas, por más que existan normas que efectivamente pareciesen limitar la autonomía indígena "a los derechos y libertades de los demás" y a las restricciones necesarias "para satisfacer las justas y más apremiantes necesidades de una sociedad democrática" ${ }^{56}$, no es posible sostener que con ello se refiere a que todos los derechos individuales -y en todos los casos- primen sobre las costumbres e instituciones indígenas, so pena de volver ilusoria la protección consagrada a favor de los pueblos indígenas. Analíticamente, esta conclusión descansa en dos supuestos: por un lado, (i) que la aplicación de los derechos humanos como reglas conclusivas haría lógicamente imposible el reconocimiento del derecho a la diferencia indígena; por otro, (ii) que el orden internacional ha avanzado en el reconocimiento de los derechos de los pueblos indígenas hasta llegar a considerarlos como sujetos colectivos de derechos fundamentales, por lo que, al igual que el caso colombiano, son titulares de un derecho a la supervivencia e integridad cultural. La conjugación correcta de ambos elementos lleva indefectiblemente a colegir que, si se quiere mantener un mínimo de coherencia en el ordenamiento jurídico internacional, no es posible entender que los derechos individuales tienen una primacía absoluta sobre el derecho propio indígena.

\section{(i) Derechos humanos y la posibilidad de diferencia indígena}

Como ha explicado Anthony Padgen, existe un vínculo inextricable entre los derechos contenidos en las declaraciones internacionales de derechos humanos y la forma específica de organización social necesaria para su concreción ${ }^{57}$. Por ejemplo, los derechos políticos específicos del Pacto Internacional de Derechos Civiles y Políticos (PIDCP) no pueden ser hechos inteligibles sino a través de un orden político determinado, a saber, el de un gobierno republicano de carácter representativo ${ }^{58}$.

Por ende, si se entiende que aquellos "derechos humanos internacionalmente reconocidos" que limitan la autonomía indígena son "todos" -o "algunos en

\footnotetext{
${ }^{55} \mathrm{~V}$. gr., respecto a la restricción de la libertad de culto, Álvaro de Jesús Torres Forero contra las autoridades tradicionales de la Comunidad Indígena Arhuaca de la zona oriental de la Sierra Nevada de Santa Marta, Corte Constitucional de Colombia, acción de tutela, 18 de septiembre de 1998. En: http:// www.corteconstitucional.gov.co/relatoria/1998/su510-98.htm [visitado el 16/07/2011].

${ }^{56}$ Art. 46.2 DDPI.

57 Pagden, Anthony, "Human Rights, Natural Rights, and Europe's Imperial Legacy", Political Theory, vol. 31, No 2, 2003, p. 192.

${ }^{58}$ Pagden, "Human Rights", cit. nota n. 57, p. 190.
} 
todos los casos" - los derechos individuales heredados de la tradición francesa y anglosajona, entonces, por lógica, se anula la posibilidad de una sociedad o comunidad indígena cualitativamente diferente a la prescrita por el imaginario occidental. Como señala el profesor de la Universidad de Viena, René Kuppe, al referirse al art. 46.1 de la Declaración: "[l]a imposición indiferenciada de las instituciones de derechos humanos y libertades fundamentales sobre la dinámica de la autonomía indígena (y sobre sus distintos poderes) impondría los valores de la sociedad occidental-dominante a las culturas indígenas. Además, algunos de los derechos humanos serían verdaderamente inaplicables dentro del contexto de organización social indígena" ${ }^{\prime 59}$. La desarticulación del derecho consuetudinario de manejo del agua del pueblo Aymara, producida por la entrada en vigencia del Código de Aguas en 1981, que consagra el paradigma del derecho de propiedad individual, es un ejemplo en este sentido ${ }^{60}$.

\section{(ii) Titularidad colectiva iusfundamental y supervivencia cultural}

Ahora bien, es claro que no habría ningún problema argumentativo con sostener la idea de una "imposición indiferenciada de los derechos humanos", si el ordenamiento jurídico internacional consagrara un paradigma normativo de carácter monista y culturalmente homogéneo, tal cual lo hacía sólo un par de décadas atrás. El problema con esto es que justamente dicho paradigma está obsoleto y, al contrario, hoy en día el sistema internacional -y en menor medida los sistemas jurídicos internos, incluido Chile $^{61}$ - es profuso en la protección

\footnotetext{
${ }^{59}$ Kuppe, René, "Autonomía de los pueblos indígenas -la perspectiva desde la Declaración de los derechos de los pueblos indígenas-", en González, M., Burguete Cal y Mayor, A., y Ortiz., P. (Coord.), La autonomía a debate. Autogobierno indígena y Estado plurinacional en América Latina. FLACSO/ GTZ/IWGIA/CIESAS/UNICH, Ecuador, 2010, p. 132.

${ }^{60}$ Véase CARMONA, Cristóbal, "Pueblos indígenas y la tolerancia occidental: los derechos humanos como forma sublimada de asimilación", Polis, vol. 8, № 23, 2009, pp. 308-311.

${ }^{61}$ Sobre los cambios de paradigmas en el constitucionalismo latinoamericano, véase YRIGOYeN, Raquel, "El horizonte del constitucionalismo pluralista: del multiculturalismo a la descolonización", en Rodríguez Garavito (Coord.), El derecho en América. Un mapa para el pensamiento jurídico del siglo XXI, Ed. Siglo XXI Editores, Buenos Aires, 2011, pp. 139-159. En el caso chileno, por más que la Ley Indígena establezca límites más estrechos al pluralismo jurídico (arts. 7 y 54), en razón del criterio de exclusión acumulativa que establece el art. 8.2 del Convenio 169, la OIT ha estimado que no se pueden emplear las normas nacionales que sean incompatibles con los derechos humanos, para justificar el desconocimiento de las costumbres de los pueblos indígenas. OIT, Los derechos de los pueblos indígenas y tribales en la práctica. Una guía sobre el Convenio núm. 169 de la OIT, 2009, p. 82. En este orden de ideas se debe relevar el cambio que últimamente ha operado en la jurisprudencia, en el sentido de reconocer explícitamente que el Convenio es un tratado de derechos humanos de aquellos a los que se refiere el art. $5^{\circ}$ inc. $2^{\circ}$ de la CPR, tal como se aprecia en el reciente fallo del TC sobre la Ley de Pesca (Requerimiento presentado por un grupo de Senadores, que representan más de la cuarta parte de los miembros en ejercicio del Senado, para que se declare la inconstitucionalidad de algunos artículos del proyecto de ley que modifica la Ley General de Pesca y Acuicultura, Tribunal
} 
de la integridad cultural y el derecho a la autodeterminación de los pueblos indígenas, lo que se evidencia no sólo en los instrumentos específicos sobre el tópico -viz., el Convenio y la Declaración-, sino incluso en los tratados más elementales sobre derechos individuales. La interpretación progresiva hecha por el Comité de Derechos Humanos (Comité) de los arts. 1 (libre determinación) y 27 (protección de minorías) del PIDCP, la carta liberal por antonomasia, nos puede dar un buen ejemplo de ello.

Es sabido que, en un comienzo, el Comité interpretó el art. 1 del Pacto siguiendo las intenciones de los estados, relacionándolo estrictamente a la independencia de los territorios bajo administración colonial, mientras que a través del art. 27 -que buscaba proteger la libertad de cada individuo para usar su lengua, disfrutar de su cultura y practicar su religión sin intromisión del Estado- el Comité canalizaba las reclamaciones de los miembros de los pueblos indígenas ${ }^{62}$. El núcleo de la diferenciación que hacía el Comité se encontraba en los sujetos activos de las normas: a "los pueblos" les correspondía la "libre determinación", y a "los individuos" indígenas la protección de su capacidad -individual y colectiva- para vivir su cultura minoritaria. Sin embargo, como ha mostrado Helen Quane, desde 1998 hasta la fecha se registra una paulatina tendencia a que, en las Observaciones Finales y Recomendaciones a los informes presentados por los estados en virtud del artículo 40 del PIDCP, el Comité incluya, junto al art. 27, al art. 1 como aquellos que protegen los derechos de los pueblos indígenas, y que los estados tienen el deber de respetar ${ }^{63}$. En los últimos años, también el Comité DESC -encargado del monitoreo del Pacto Internacional de Derechos Económicos Sociales y Culturales (DESC)- ha adoptado una actitud semejante respecto a la libre determinación de los pueblos indígenas (art. 1), relacionándolo con el derecho a participar en la vida cultural (art. 15.1.a), tanto en sus Observaciones Finales a los estados ${ }^{64}$ como en su Observación

Constitucional de Chile, requerimiento por inconstitucionalidad, 23 de enero de 2013, Considerando $12^{\circ}$. En: http://www.tribunalconstitucional.cl/wp/ver.php?id=2667 [visitado el 13/02/2013]). Sobre las reticencias de la doctrina de reconocer al Convenio 169 como tratado de DDHH, véase GAETE URIBE, Lucía, "El Convenio № 169. Un análisis de sus categorías problemáticas a la luz de su historia normativa", Revista lus et Praxis, Año 2, № 18, 2012, pp. 107 y ss.

${ }^{62}$ Sobre la historia de la aplicación de ambos artículos respecto de los pueblos indígenas, ver las obras señaladas Supra, nota 8. Por lo demás, esta distinción categórica entre el significado y la utilización ambos artículos la encontramos incluso en documentos tan recientes como la Observación General № 23 del Comité sobre el art. 27, de 1994. Véase ONU, Comité de Derechos Humanos, Observación General № 23: El derecho de las minorías (art. 27), 1994, CCPR/C/21/Rev.1/Add.5 párr. 3.1.

${ }^{63}$ Quane, Helen, "A Further Dimension to the interdependence and Indivisibility of Human Rights?: Recent Developments Concerning the Rights of Indigenous Peoples", Harvard Human Rights Journal, vol. 25, 2012, pp. 61 y ss.

${ }^{64}$ QuANE, Helen, "A Further", cit. nota n. 63, pp. 69 y 70. 
General No 21 de 2009, referida, justamente, a este derecho ${ }^{65}$. Esta tendencia es importante, pues muestra que, de manera independiente de sus miembros, los pueblos indígenas han adquirido la titularidad de derechos fundamentales ${ }^{66}$, partiendo por el más básico -reconocido incluso a nivel interno como derecho fundamental por los tribunales constitucionales de Perú ${ }^{67}$ y Colombia ${ }^{68}-$ : el derecho a existir y a perseverar en su identidad cultural.

En el SIDH, es interesante notar que la evolución de la Corte Interamericana en su jurisprudencia sobre derechos indígenas, avanza en el mismo sentido ${ }^{69}$. Hasta el Caso Comunidad Indígena Xákmok Kásek Vs. Paraguay inclusive -de agosto de 2010-, en sus principales sentencias respecto al tema ${ }^{70}$, la Corte había determinado violaciones de derechos humanos en perjuicio de los "integrantes"

65 "El derecho a participar en la vida cultural es también interdependiente de otros derechos enunciados en el Pacto, como el derecho de todos los pueblos a la libre determinación (art. 1)". ONU, Comité DESC, Observación General № 21. Derecho de toda persona a participar en la vida cultural (artículo 15, párrafo 1 a), 2009, E/C.12/GC/21/Rev.1, párr. 2).

66 "[... los pueblos indígenas, que tienen derecho, colectiva o individualmente, al disfrute pleno de todos los derechos humanos y libertades fundamentales reconocidos por la Carta de las Naciones Unidas, la Declaración Universal de Derechos Humanos, las normas internacionales de derechos humanos y la Declaración de las Naciones Unidas sobre los derechos de los pueblos indígenas"; "En su Observación general $N^{0} 17(\ldots)$, el Comité reconoce que la expresión 'toda persona' se refiere tanto al sujeto individual como al sujeto colectivo. En otras palabras, una persona puede ejercer los derechos culturales: a) individualmente; b) en asociación con otras; o c) dentro de una comunidad o un grupo". Íd., párr. 7 y 9 . El énfasis es mío.

${ }^{67}$ Véase Jaime Hans Bustamente contra Occidental Petrolera del Perú y otras, Tribunal Constitucional del Perú, recurso de agravio constitucional, 19 de febrero de 2009, fundamento 29. En: http://www. tc.gob.pe/jurisprudencia/2009/03343-2007-AA.html [visitado el 09/05/2013].

${ }^{68}$ Véase Organización Indígena de Antioquia (O.I.A.), agente oficioso de la Comunidad Indígena Embera-Catio de Chajerado, contra la Corporación Nacional de Desarrollo Del Choco (Codechoco) y la Compañía de Maderas del Darien (Madarien), Corte Constitucional de Colombia, acción de tutela, 13 de septiembre de 1993. En: http://www.corteconstitucional.gov.co/relatoria/1993/T-380-93.htm [visitado el 09/08/2012].

${ }^{69}$ A continuación se sigue en lo pertinente la argumentación del Voto Concurrente del Juez Eduardo Vio Grossi en Comunidad Indígena Xákmok Kásek Vs. Paraguay, de la Corte IDH, Sentencia de Fondo, Reparaciones y Costas, 24 de agosto de 2010. En: http://www.corteidh.or.cr/docs/casos/articulos/ seriec_214_esp. pdf [visitado el 19/06/2012].

${ }^{70}$ Véase Comunidad Mayagna (Sumo) Awas Tingni Vs. Nicaragua, Corte IDH, Sentencia de Fondo, Reparaciones y Costas, 31 de agosto de 2001. En: http://www.corteidh.or.cr/docs/casos/articulos/ seriec_79_esp. pdf [visitado el 30/06/2011]; Comunidad Indígena Yakye Axa Vs. Paraguay, Corte IDH, Sentencia de Fondo Reparaciones y Costas, 17 de junio de 2005. En: http://www.corteidh.or.cr/docs/ casos/articulos/seriec_125_esp. pdf [visitado el 10/10/2012]; Comunidad Indígena Sawhoyamaxa Vs. Paraguay, Corte IDH, Sentencia de Fondo, Reparaciones y Costas Caso, 29 de marzo de 2006. En: http://www.corteidh.or.cr/docs/casos/articulos/seriec_146_esp2.pdf [visitado el 27/05/2012]; y Pueblo Saramaka Vs. Surinam, Corte IDH, Sentencia de Excepciones Preliminares, Fondo, Reparaciones y Costas, 28 de noviembre de 2007. En: http://www.corteidh.or.cr/docs/casos/articulos/seriec_172_esp. pdf [visitado el 11/12/2012]. 
o "miembros" de los pueblos indígenas, sin hacer referencia explícita al "pueblo indígena" como sujeto colectivo de derecho. Y si bien en la citada sentencia la Corte sigue considerando como parte lesionada "a los miembros de la Comunidad Xákmok Kásek"71, también -y así lo notó en su voto concurrente el juez chileno Vio Grossi- se refirió a la comunidad misma como el sujeto colectivo que reclama derechos, principalmente en lo que dice relación con el derecho al territorio ${ }^{72}$ y a la propiedad comunitaria ${ }^{73}$. Pues bien, finalmente, en Pueblo Indígena Kichwa de Sarayaku Vs. Ecuador, de julio de 2012, la Corte IDH opta por esta última línea argumentativa, reconociendo que, aun cuando anteriormente había declarado violaciones referentes a los "miembros" en este tipo de casos, estima ahora que:

[...] la normativa internacional relativa a pueblos y comunidades indígenas o tribales reconoce derechos a los pueblos como sujetos colectivos del Derecho Internacional y no únicamente a sus miembros. Puesto que los pueblos y comunidades indígenas o tribales, cohesionados por sus particulares formas de vida e identidad, ejercen algunos derechos reconocidos por la Convención desde una dimensión colectiva, la Corte señala que las consideraciones de derecho expresadas o vertidas en la presente Sentencia deben entenderse desde dicha perspectiva colectiva ${ }^{74}$.

En síntesis, si se considera que (i) una aplicación formalista y mecánica de los derechos humanos imposibilita la supervivencia cultural de los pueblos indígenas, y que (ii) el orden internacional contemporáneo respecto a los derechos de los pueblos indígenas, estima que estos pueblos también son titulares de derechos fundamentales -como el mantener su integridad cultural-, entonces no es posible sostener una reconstrucción del ordenamiento jurídico que subordine inexorablemente el derecho propio indígena -expresión de su derecho fundamental a mantener su identidad cultural y elemento necesario para ejercer su derecho a la libre determinación y al territorio ${ }^{75}$ - a los derechos fundamentales de la persona. Una interpretación de este tipo, como lo expresó la Corte IDH respecto del derecho de propiedad, "equivaldría a sostener que sólo existe una forma de usar y disponer de los bienes, lo que a su vez significaría hacer ilusoria la protección del art. 21 de la Convención para millones de personas ${ }^{\prime \prime 76}$.

De aquí que la forma jurídicamente correcta de afrontar un caso en donde exista una oposición como la que venimos discutiendo, es aceptando que nos

\footnotetext{
${ }^{71}$ Caso Comunidad Indígena Xákmok Kásek Vs. Paraguay, Corte IDH, cit. nota 69, párr. 278.

${ }^{72}$ Caso Comunidad Indígena Xákmok Vs. Paraguay, Corte IDH, cit. nota n. 69, párr. 64 y ss.

${ }^{73}$ Caso Comunidad Indígena Xákmok Vs. Paraguay, Corte IDH, cit. nota n. 69, párr. 85 y ss.

${ }^{74}$ Pueblo Indígena Kichwa de Sarayaku Vs. Ecuador, Corte IDH, cit. nota n. 23, párr. 231.

${ }^{75}$ Pueblo Indígena Kichwa de Sarayaku Vs. Ecuador, Corte IDH, cit. nota n. 23, párr. 159.

${ }^{76}$ Comunidad Indígena Sawhoyamaxa Vs. Paraguay, Corte IDH, cit. nota n. 70, párr. 120.
} 
encontramos ante dos normas respecto de las cuales las convenciones interpretativas existentes no predeterminan relaciones de preferencia claras entre ellas para los casos en que colisionen -como señaló la Corte IDH, que tanto la propiedad privada de los particulares como la propiedad comunitaria indígena, se encuentran amparadas por la Convención Americana ${ }^{77}$-, sino que su aplicación requiere "siempre de una decisión discrecional entre alternativas abiertas por parte del aplicador acerca de la relevancia o irrelevancia de cualesquiera propiedades del caso concreto distintas de las que definen su supuesto de hecho $^{\prime \prime 8}$-haciéndolas, por tanto, derrotables-.

Concretamente, en algunas oportunidades el ejercicio del derecho a consulta a través de las instituciones representativas implicará cierto tipo de restricción a la libertad individual de algún miembro en lo que a participación política concierne, sea porque la lógica comunitaria de elección y organización de las instituciones representativas así lo mandata, o porque la afectación tiene una dimensión predominantemente colectiva, o, incluso, porque un miembro puede verse afecto a una sanción específica que lo margine de ciertos procesos deliberativos. En estos casos, sabiendo ahora que no sólo el miembro de la comunidad es titular de un derecho individual a la participación, sino que la comunidad "en sí" tiene, inter alia, el derecho colectivo fundamental a mantener su integridad cultural -el que está vinculado con la capacidad que tenga para conservar sus instituciones y formas de organización-, es que la autoridad pública deberá definir, de acuerdo a las circunstancias específicas del caso, cuál de estos derechos (individual o colectivo) será finalmente "restringido" o, en los términos que se viene describiendo, "derrotado" -lo que, por lo demás, no es ajeno a la arquitectura normativa internacional ${ }^{79}$ ni constitucional ${ }^{80}-$.

\footnotetext{
${ }^{77}$ Comunidad Indígena Yakye Axa Vs. Paraguay, Corte IDH, cit. nota n. 70, párr. 143.

${ }^{78}$ BAYón, Derrotabilidad, cit. nota n. 29, p. 109. En este punto, muchas veces no se será posible demostrar que la decisión tomada era la única respuesta correcta posible, pero ello -como reconocía Hart- no quiere decir que ésta no pueda ser considerada, al mismo tiempo, como el producto razonado de una elección informada e imparcial. HART, The concept, cit. nota n. 33, p. 205.

79 "(...) a few rights in each system are treated as categorical or peremptory norms, permitting no limitations or derogations. Apart from these, the primary conception of rights is as presumptive shields rather than as absolute trumps, permitting them in principle to be justifiably limited or overridden where necessary to promote important but conflicting public policy objectives". GARDBAUM, Stephen, "Human rights and international constitutionalism". Ponencia presentada en "Ruling the World? Constitutionalism, International Law \& Global Government", diciembre 2007. En: http://papers.ssrn.com/ sol3/papers.cfm?abstract_id=1088039 [visitado el 23/04/13].

${ }^{80}$ Clavero ha subrayado cómo los derechos individuales siempre han estado a la sombra de un derecho colectivo, "el derecho estatal de condicionar, limitar e incluso excluir derechos individuales"; este es un derecho, dice el jurista español, que se predica del pueblo antes que del estado, "es derecho de pueblo" y, por tanto, común tanto al estado no indígena y a la comunidad indígena. CLAVERO, Bartolomé, Derecho indígena y cultura constitucional en América, Siglo XXI Editores, México, 1994, pp. 119 y 120.
} 
"Tomando los derechos colectivos en serio: el derecho a consulta previa del Convenio 169 de la OIT y las instituciones representativas de los pueblos indígenas"

\section{A MODO DE CONCLUSIÓN:}

\section{LAS INSTITUCIONES REPRESENTATIVAS EN LA CONSULTA INDÍGENA DEL SEIA}

En el año 2007, el en ese entonces Relator Especial para los derechos de los pueblos indígenas Rodolfo Stavenhagen, señalaba la existencia de una "brecha de implementación", esto es, una distancia o hiato que mediaba entre el reconocimiento de derechos y la efectiva implementación de estos; dicha brecha, decía, era particularmente relevante cuando se refería a las inconsistencias entre la normativa -sea internacional, constitucional y/o de legislación secundaria- "indígena", y las leyes sectoriales que regulan la explotación de recursos naturales ${ }^{81}$. En nuestro país, el Reglamento del SEIA que fuera aprobado el 28 de mayo del 2012 por el Consejo de Ministros para la Sustentabilidad ${ }^{82}$, era un claro ejemplo de un marco normativo inconsistente respecto a lo dispuesto en el estándar del Convenio 169, inter alia, en lo referente al sujeto de la consulta.

En efecto, en su art. 85, bajo el epígrafe de "Participación y consulta indígena", el Reglamento establecía el deber para el administrador ambiental de "desarrollar un proceso de participación y diálogo" que permitiese la "participación informada" de los "grupos humanos indígenas" en la evaluación ambiental del proyecto. Como es evidente, el desplazamiento semántico del sujeto de la consulta que operaba en este artículo -desde "el pueblo interesado a través de sus instituciones representativas" hasta los "grupos humanos indígenas"-, no era baladí, pues reducía significativamente la densidad normativa de la obligación estatal, disolviendo la perspectiva colectiva del derecho al disgregarlo en ese ente difuso que sería el "grupo humano indígena". En otras palabras, el derecho perdía su carácter colectivo y el Estado se sustraía del deber de determinar cuáles eran las instituciones "verdaderamente" representativas del pueblo al que se le va a consultar. Asimismo, esta relajación del estándar normativo podía permitir que el titular de un proyecto de inversión -fuese público o privadollevara adelante procesos de negociación con los miembros desagregados o con fracciones de esos grupos humanos indígenas. Esto último, se mencionó supra, es incompatible con una consulta de buena fe.

Sin embargo, el Reglamento del SEIA que ingresó a Contraloría para toma de razón ${ }^{83}$ y que, finalmente, fue publicado en agosto de este año ${ }^{84}$, lo hizo con un cambio sustantivo respecto de la versión analizada en el párrafo precedente.

\footnotetext{
${ }^{81} \mathrm{HRC}$, Informe del Relator Especial sobre la situación de los derechos humanos y las libertades fundamentales de los indígenas, Rodolfo Stavenhagen, 2007, A/HRC/4/32, párr. 5.

${ }^{82}$ Ministerio del Medio Ambiente, Consejo de Ministros para la Sustentabilidad, Acuerdo No 8/2012, 28 de mayo de 2012.

${ }^{83}$ Ministerio del Medio Ambiente, Ord. MMA No 130114, 10 de enero de 2013.

${ }^{84}$ Ministerio del Medio Ambiente, D.S. No 40/2012, publicado en el Diario Oficial el día 12 de agosto de 2013.
} 
En efecto, y si bien continúa "desalineado" con el estándar del Convenio en materia de susceptibilidad de afectación, el nuevo art. 85, junto con reconocer que el deber del SEA no es ya el de "desarrollar un proceso de participación y diálogo", sino de "diseñar y desarrollar un proceso de consulta de buena fe", establece que este proceso deberá llevarse a cabo a través de las "instituciones representativas" de cada pueblo. Con ello, se restituye la cualidad colectiva al derecho a consulta, garantizando asimismo -en virtud de la doble naturaleza y objeto de este derecho ${ }^{85}$ - la observancia de otros derechos sustantivos de los pueblos indígenas $-v$. gr., a la protección de los recursos naturales presentes en su territorio-. Esta modificación, claro está, no obsta a que las instituciones representativas con las que se efectuó la consulta puedan ser impugnadas bajo las bases normativas acá revisadas; pero, ahora, el marco regulatorio ambiental no presenta una brecha tan amplia respecto del estándar internacional en este tópico (instituciones representativas), lo que sumado a la cada vez mayor comprensión de la jurisprudencia nacional -tanto en materia civil, penal y constitucional- del carácter de "tratado de derechos humanos" del Convenio, contribuye a proporcionar los elementos suficientes para que, ante alguna eventual antinomia entre derechos colectivos y derechos individuales que se dé en el contexto de la evaluación ambiental -por ejemplo, que la institución representativa sea una autoridad tradicional elegida de forma no democráticala autoridad pública pueda ponderar correctamente los derechos en conflicto, en busca de una solución adecuada al caso concreto.

Obviamente, esto no quiere decir que el Estado desatienda los derechos fundamentales de las personas en las dinámicas de las relaciones intracomunitarias, ni que haya una prioridad establecida del colectivo sobre el individuo. Al contrario, de lo que se trata es precisamente de abandonar una lógica maniquea similar, de reconocer que la configuración actual del ordenamiento jurídico implica una ponderación de los bienes jurídicos que hay en juego, y de resguardar a los propios derechos fundamentales individuales de su uso ideológico ${ }^{86}$. En otras palabras, de lo que se trata es de tomarse en serio el que la consulta es un derecho colectivo, cuyo titular es el pueblo indígena a través de sus instituciones representativas, en tanto sujeto colectivo de derechos fundamentales.

\footnotetext{
${ }^{85}$ Como explica Raquel Yrigoyen: "De un lado, se trata de derechos propios, con su propio contenido sustantivo vinculado a la dignidad de los pueblos (...) De otro, se trata de derechos que buscan realizar o viabilizar otros derechos en el marco de la relación entre Estados y pueblos indígenas, y están vinculados a la capacidad de los pueblos para controlar sus instituciones, definir su modelo y prioridades de desarrollo, la protección de territorio, su integridad física y cultural, etc.". YRIGOYEN, Raquel, "De la tutela indígena a la libre determinación del desarrollo, participación, consulta y consentimiento", Instituto Internacional de Derecho y Sociedad-IIDSS, Lima, 2009, p. 16.

${ }^{86}$ Sobre el uso ideológico de los derechos humanos, véase KrмlıскA, Will, "Human Rights and Ethnocultural Justice", Review of Constitutional Studies, vol. IV. № 2, 1998, p. 222.
} 


\section{BiBLIOGRAFÍA CITADA}

\section{Artículos y libros}

Anaya, James, Los pueblos indígenas en el derecho internacional, Segunda edición, Editorial Trotta, Madrid, 2005.

"The right of indigenous peoples to self determination in the postdeclaration era", en Charters, C. y Stavenhagen, R, Making the Declaration work. The United Nations Declaration on the Rights of Indigenous Peoples, IWGIA, Copenhague, 2009.

AtriA, Fernando, On Law and Legal Reasoning, Hart Publishing, Londres, 2002.

"Ubi ius, ibi remedium? La relevancia jurídica de los derechos humanos", Revista de Estudios de la Justicia, № 3, 2003.

BAYÓN, Juan Carlos, "Derrotabilidad, indeterminación del derecho y positivismo jurídico", Isonomía, № 13, octubre 2000.

BerRaOndo, Mikel, "Tierras y territorios como elementos sustantivos del derecho humano al medio ambiente", en BerRaOndo, M. (Coord.), Pueblos Indígenas y Derechos Humanos, Universidad de Deusto, Bilbao, 2006.

CARmOna, Cristóbal, "Pueblos indígenas y la tolerancia occidental: los derechos humanos como forma sublimada de asimilación", Polis, vol. 8 № 23, 2009.

Clavero, Bartolomé, Derecho indígena y cultura constitucional en América, Siglo XXI Editores, México, 1994.

CONTESSE, Jorge, "El derecho de consulta previa en el Convenio 169 de la OIT. Notas para su implementación en Chile", en ConTESSE, Jorge (Ed.), El Convenio 169 de la OIT y el derecho chileno, Mecanismos y obstáculos para su implementación, Ediciones UDP, Santiago, 2012.

CONTESSE, J. y LoverA, D., "El Convenio 169 de la OIT en la jurisprudencia chilena: prólogo del incumplimiento", en Anuario de Derecho Público 2011, Editorial Universidad Diego Portales, Santiago, Chile, 2011.

ECHEverRía Turres, Claudia, "División sexual del trabajo y matrimonio aymara contemporáneo desde una perspectiva de género", Revista de Ciencias Sociales (Universidad Arturo Prat), № 8, 1998.

Faúndes PeÑafiel, Juan Jorge, "Primera sentencia que aplica el convenio No 169 de la OIT en Chile. Derecho a vivir en un medio ambiente libre de contaminación comprende el concepto de territorio, hábitat y protección de la cultura de los pueblos indígenas", Revista Chilena de Derecho y Ciencia Política, vol. 1 № 1, 2010.

Fernández Grossetete, María de los Ángeles, Historia sistematizada de la ley 20.417: instrumentos de gestión ambiental y otros temas, Memoria para 
optar al grado de Licenciatura en Ciencias Sociales y Jurídicas, Universidad de Chile, Santiago, 2013.

Gaete Uribe, Lucía, "El Convenio № 169. Un análisis de sus categorías problemáticas a la luz de su historia normativa", Revista lus et Praxis, Año 2, № 18, 2012.

HART, H. L. A. "The ascription of responsibility and rights", en Flew, A. (Ed.), Logic and Language, Basil Blackwell, Oxford, 1951.

, "Jhering's Heaven of Concepts and Modern Analytical Jurisprudence", en Essays in Jurisprudence and Philosophy, Clarendon Press, Oxford, 1983.

, The Concept of law, Segunda edición, Oxford University Press, Oxford, 1997.

KymlıckA, Will, Multicultural Citizenship. A liberal theory of minority rights, Oxford University Press, Oxford, 1996.

, "Human Rights and Ethnocultural Justice", Review of Constitutional Studies, vol. IV. № 2, 1998.

, "Teoría de los derechos indígenas", en La política vernácula. Nacionalismo, multiculturalismo y ciudadanía, Paidós, Barcelona, 2003.

"Testing the bounds of liberal multiculturalism", Ponencia presentada en la conferencia Muslim women's equality rights in the justice system: gender, religion and pluralism, abril 2005. En: http://www.trudeaufoundation.ca/ resource/public/communiq/2006coll [visitado el 16/06/2012].

Multicultural Odysseys. Navigating the New International Politics of Diversity, Oxford University Press, Nueva York, 2007.

KuPPE, René, "Autonomía de los pueblos indígenas -la perspectiva desde la Declaración de los derechos de los pueblos indígenas-", en GonzÁlez, M., Burguete Cal y Mayor, A., y Ortiz-T., P. (Coord.), La autonomía a debate. Autogobierno indígena y Estado plurinacional en América Latina, FLACSO/ GTZ/IWGIA/CIESAS/UNICH, Ecuador, 2010.

Moreira, Manuel, "Los desafíos del 'pluralismo jurídico': sistema plurilegal o interlegalidad", Antropología y Derecho, Año 5, № 8, 2011.

Pagden, Anthony, "Human Rights, Natural Rights, and Europe's Imperial Legacy", Political Theory, vol. 31, № 2, 2003.

Quane, Helen, "A Further Dimension to the interdependence and Indivisibility of Human Rights?: Recent Developments Concerning the Rights of Indigenous Peoples", Harvard Human Rights Journal, vol. 25, 2012.

ReYES, Francisco, "Participación indígena en los partidos políticos", en Desafíos de la participación política indígena y de las políticas públicas para los pueblos indígenas en Latinoamérica, Fundación Konrad Adenauer (KAS)/ UCT, Temuco, 2011. 
Rodríguez Garavito, César, Etnicidad.gov. Los recursos naturales, los pueblos indígenas y el derecho a la consulta previa en los campos sociales minados, Centro de Estudios de Derecho, Justicia y Sociedad, Dejusticia, Bogotá, 2012.

Rodríguez, J. y Sucar, G., "Las trampas de la derrotabilidad. Niveles de análisis de la indeterminación del derecho", en Analisi e Diritto, 1998.

Salgado, J. M. y Gomiz, M. M., Convenio 169 de la O.I.T. sobre Pueblos Indígenas: su aplicación en el derecho interno argentino, $2^{\text {a }}$ edición, Observatorio de Derechos Humanos de los pueblos Indígenas, Neuquén, 2010.

SChilling-VACAflOR, Almut, "Democratizing Resource Governance through Prior Consultations? Lessons from Bolivia's Hydrocarbon Sector", Giga Working Papers, № 184, January 2012.

SIERRA, María Teresa, "Esencialismo y autonomía: paradojas de las reivindicaciones indígenas", Alteridades, año 7, № 14, 1997.

UGARTE, José Luis, "Los derechos en su nueva hora: la teoría externa de los derechos fundamentales", Revista de Derecho Universidad (Católica del Norte), Año 18-No 2, 2011.

YRIGOYEN, Raquel, "De la tutela indígena a la libre determinación del desarrollo, participación, consulta y consentimiento", Instituto Internacional de Derecho y Sociedad- IIDSS, Lima, 2009.

, "El horizonte del constitucionalismo pluralista: del multiculturalismo a la descolonización", en Rodríguez Garavito (Coord.), El derecho en América. Un mapa para el pensamiento jurídico del siglo XXI, Ed. Siglo XXI Editores, Buenos Aires, 2011.

\section{Documentos}

CIDH, Mary y Carrie Dann (Estados Unidos), Informe No 75/02, Caso 11.140, 27 de diciembre de 2002.

Comité de Derechos Humanos, Observación General № 23: El derecho de las minorías (art. 27), 1994, CCPR/C/21/Rev.1/Add.5.

Comité DESC, Observación General № 21. Derecho de toda persona a participar en la vida cultural (artículo 15, párrafo 1 a), 2009, E/C.12/GC/21/Rev.1).

Corte IDH, Condición Jurídica y Derechos de los Migrantes Indocumentados. Opinión Consultiva OC-18/03. Serie A No 18, 17 de septiembre de 2003.

HRC, Informe del Relator Especial sobre la situación de los derechos humanos y las libertades fundamentales de los indígenas, Rodolfo Stavenhagen, marzo de 2007, A/HRC/4/32, párr. 5.

, Relator Especial de las Naciones Unidas sobre la situación de los derechos humanos y las libertades fundamentales de los indígenas, James 
Anaya, Principios internacionales aplicables a la consulta en relación con la reforma constitucional en materia de derechos de los pueblos indígenas en Chile, abril de 2009.

, Informe del Relator Especial sobre la situación de los derechos humanos y las libertades fundamentales de los indígenas, James Anaya, octubre de 2009, A/HRC/12/34.

, Estándares del deber de consulta. Comentarios del Relator Especial a la Propuesta de Reglamento de Consulta del Gobierno de Chile, noviembre de 2012. En: http://www.politicaspublicas.net/panel/re/docs/1654-comentarioreglamento-chile.html [visitado el 13/01/13].

Informe del Relator Especial sobre la situación de los derechos humanos y las libertades fundamentales de los indígenas, James Anaya. Las industrias extractivas y los pueblos indígenas, 1 de julio de 2013, A/HRC/24/41.

Ministerio del Medio Ambiente, Consejo de Ministros para la Sustentabilidad, Acuerdo No 8/2012, 28 de mayo de 2012.

, Ord. MMA No 130114, 10 de enero de 2013.

OIT, Consejo de Administración, 282 ${ }^{a}$ reunión. Reclamación presentada en virtud del artículo 24 de la Constitución de la OIT, Ecuador, 2 de noviembre de 2001,GB.282/14/.

, Consejo de Administración, 289a reunión, Reclamación presentada en virtud del artículo 24 de la Constitución de la OIT, México, marzo de 2004., GB.289/17/3.

, Los derechos de los pueblos indígenas y tribales en la práctica. Una guía sobre el Convenio núm. 169 de la OIT, 2009.

CEACR, Solicitud Directa, adopted 2010, published 100th ILC session (2011). En http://www.ilo.org/dyn/normlex/en/f?p=1000:13100:0::NO::P13100_ COMMENT_ID,P13100_LANG_CODE:2334939,es:NO [visitado el 22/10/2012].

\section{Jurisprudencia}

Alejandro Papic Domínguez con Comunidad Indígena Aymara Chuzmiza y Usmagama, Corte Suprema, regularización derechos de aprovechamiento de agua, 25 de noviembre de 2009. En: http://suprema.poderjudicial.cI/SITSUPPORWEB/DownloadFile.do?TIP_Documento=3\&TIP_ Archivo=3\&COD_Opcion=1\&COD_Corte $=1 \&$ CRR_IdTramite $=517143 \& C R R \_$ IdDocumento=300721 [visitado el 15/04/2010].

Álvaro Bailarín y otros, contra los Ministerios del Interior y de Justicia; de Ambiente, Vivienda y Desarrollo Territorial; de Defensa; de Protección Social; y de Minas y Energía, Corte Constitucional de Colombia, acción de 
tutela, 29 de octubre de 2009. En: http://www.corteconstitucional.gov.co/ relatoria/2009/t-769-09.htm [visitado el 29/03/2011].

Álvaro de Jesús Torres Forero contra las autoridades tradicionales de la Comunidad Indígena Arhuaca de la zona oriental de la Sierra Nevada de Santa Marta, Corte Constitucional de Colombia, acción de tutela, 18 de septiembre de 1998. En: http://www.corteconstitucional.gov.co/relatoria/1998/su510-98. htm [visitado el 16/07/2011].

Asociación Indígena Consejo de Pueblos Atacameños con Comisión Regional del Medio Ambiente Región Antofagasta, Corte Suprema, Recurso de Protección, 13 de julio de 2011. En: http://suprema.poderjudicial.cl/SITSUPPORWEB/DownloadFile.do?TIP_Documento=3\&TIP_Archivo=3\&COD_Opcion=1\&COD_ Corte $=1 \& C R R \_I d T r a m i t e=975635 \& C R R \_I d D o c u m e n t o=602580$ [visitado el 23/03/2012].

Comunidad Agrícola Los Huasco Altinos con Comisión de Evaluación III Región de Atacama, Corte Suprema, Recurso de Protección, 27 de abril de 2012. En: http://suprema.poderjudicial.cl/SITSUPPORWEB/DownloadFile.do?TIP_Documento $=3 \&$ TIP_Archivo $=1 \&$ COD_Opcion $=1 \&$ COD_ Corte $=1 \& C R R \_I d T r a m i t e=1075418 \& C R R \_I d D o c u m e n t o=671213$ [visitado el 11/05/2012].

Comunidad Indigena Antu Lafquen de Huentetique contra Comisión Regional del Medio Ambiente Región de Los Lagos, Corte Suprema, Recurso de Protección, 22 de marzo de 2012. En: http://suprema.poderjudicial.cl/SITSUPPORWEB/DownloadFile.do?TIP_Documento=3\&TIP_Archivo=1\&COD_Opcion=1\&COD_ Corte $=1 \&$ \&RR_IdTramite $=1065562 \& C R R \_I d D o c u m e n t o=662461$ [visitado el 14/06/2012].

Comunidad Indígena Sawhoyamaxa Vs. Paraguay, Corte IDH, Sentencia de Fondo, Reparaciones y Costas Caso, 29 de marzo de 2006. En: http:// www.corteidh.or.cr/docs/casos/articulos/seriec_146_esp2.pdf [visitado el 27/05/2012].

Comunidad Indígena Xákmok Kásek Vs. Paraguay, de la Corte IDH, Sentencia de Fondo, Reparaciones y Costas, 24 de agosto de 2010. En: http://www.corteidh. or.cr/docs/casos/articulos/seriec_214_esp.pdf [visitado el 19/06/2012].

Comunidad Indígena Yakye Axa Vs. Paraguay, Corte IDH, Sentencia de Fondo Reparaciones y Costas, 17 de junio de 2005. En: http://www.corteidh.or.cr/ docs/casos/articulos/seriec_125_esp.pdf [visitado el 10/10/2012].

Comunidad Mayagna (Sumo) Awas Tingni Vs. Nicaragua, Corte IDH, Sentencia de Fondo, Reparaciones y Costas, 31 de agosto de 2001. En: http://www.corteidh. or.cr/docs/casos/articulos/seriec_79_esp.pdf [visitado el 30/06/2011].

Contraloría General de la República, informa sobre recurso de protección, 17 de diciembre de 2009. En: http://www.contraloria.cl/LegisJuri/Dictamenes- 
GeneralesMunicipales.nsf/FrameSetConsultaWebAnonima?OpenFrameset [visitado el 20/11/2012].

Edith Magnolia Bastidas Calderón, Corte Constitucional de Colombia, acción pública de inconstitucionalidad, 22 de octubre de 2002. En: http://www.corteconstitucional.gov.co/relatoria/2002/c-891-02.htm [visitado el 13/03/2011]. Jaime Hans Bustamente contra Occidental Petrolera del Perú y otras, Tribunal Constitucional del Perú, recurso de agravio constitucional, 19 de febrero de 2009. En: http://www.tc.gob.pe/jurisprudencia/2009/03343-2007-AA.html [visitado el 09/05/2013].

Javier Nahuelpan y otros Contra Corema Región de Los Ríos, Corte Suprema, Recurso de Protección, 14 de octubre de 2010. En: http://suprema.poderjudicial.cl/SITSUPPORWEB/DownloadFile.do?TIP_Documento=3\&TIP_ Archivo=3\&COD_Opcion=1\&COD_Corte=1\&CRR_IdTramite=958519\&CRR_ IdDocumento=591128 [visitado el 07/08/2012].

José Narciso Jamioy Muchavisoy con Ministerio del Interior y de Justicia, Corte Constitucional de Colombia, acción de tutela, 18 de diciembre de 2009. En: http://www.corteconstitucional.gov.co/relatoria/2009/t-973-09.htm [visitado el 15/11/2012].

Linconao Huircapan Francisca contra Sociedad Palermo Ltda., Corte Suprema, recurso de protección, 30 de noviembre de 2009. En: http:// suprema.poderjudicial.cl/SITSUPPORWEB/DownloadFile.do?TIP_ Documento=3\&TIP_Archivo=3\&COD_Opcion=1\&COD_Corte $=1 \& C R R \_$ IdTramite=647053\&CRR_IdDocumento=385747 [visitado el 06/12/2011].

Marcelo Condore Vilca Consejero Territoral Alto Tarapaca y otros contra Directora Servicio de Evaluación Ambiental Primera Región de Tarapacá, Corte Suprema, Recurso de Protección, 30 de marzo de 2012. En: http://suprema.poderjudicial.cl/SITSUPPORWEB/DownloadFile.do?TIP_ Documento=3\&TIP_Archivo=1\&COD_Opcion=1 \&COD_Corte $=1 \&$ CRR_ IdTramite=1067895\&CRR_IdDocumento=664550 [visitado el 15/07/2012].

Millaray Huichalaf Pradines y otros contra Juan H. Ortiz Ortiz, Corte Suprema, Recurso de Protección, 21 de septiembre de 2012. En: http://suprema.poderjudicial.cl/SITSUPPORWEB/DownloadFile.do?TIP_ Documento=3\&TIP_Archivo=1\&COD_Opcion=1 \&COD_Corte $=1 \&$ CRR_ IdTramite=1120556\&CRR_IdDocumento=711706 [visitado el 03/10/2012].

Organización Indígena de Antioquia (O.I.A.), agente oficioso de la Comunidad Indígena Embera-Catio de Chajerado, contra la Corporación Nacional de Desarrollo Del Choco (Codechoco) y la Compañía de Maderas del Darien (Madarien), Corte Constitucional de Colombia, acción de tutela, 13 de septiembre de 1993. En: http://www.corteconstitucional.gov.co/relatoria/1993/T380-93.htm [visitado el 09/08/2012]. 
Ovidio González Wasorna con Asamblea General de Cabildos Indígenas región Chamí y Cabildo Mayor Único (CRIR), Corte Constitucional de Colombia, acción de tutela, 8 de agosto de 1996. En: http://www.corteconstitucional. gov.co/relatoria/1996/T-349-96.htm [visitado el 23/12/2011].

Pueblo Indígena Kichwa de Sarayaku Vs. Ecuador, Corte IDH, Sentencia de Fondo y Reparaciones, 27 de junio de 2012. En: http://www.corteidh.or.cr/ docs/casos/articulos/seriec_245_esp.pdf visitado el 21/07/2012].

Pueblo Saramaka Vs. Surinam, Corte IDH, Interpretación de la Sentencia de Excepciones Preliminares, Fondo, Reparaciones y Costas, 12 de agosto de 2008. En: http://www.tc.gob.pe/corte_interamericana/seriec_185_esp.pdf [visitado el 17/06/2012].

Pueblo Saramaka Vs. Surinam, Corte IDH, Sentencia de Excepciones Preliminares, Fondo, Reparaciones y Costas, 28 de noviembre de 2007. En: http:// www.corteidh.or.cr/docs/casos/articulos/seriec_172_esp.pdf [visitado el 11/12/2012].

Requerimiento presentado por un grupo de Senadores, que representan más de la cuarta parte de los miembros en ejercicio del Senado, para que se declare la inconstitucionalidad de algunos artículos del proyecto de ley que modifica la Ley General de Pesca y Acuicultura, Tribunal Constitucional de Chile, requerimiento por inconstitucionalidad, 23 de enero de 2013. En: http://www. tribunalconstitucional.cl/wp/ver.php?id=2667 [visitado el 13/02/2013].

Requerimiento presentado por un grupo de señores Diputados, que representan más de la cuarta parte de los miembros en ejercicio de la Cámara, respecto de la inconstitucionalidad del Convenio $N^{\circ} 169$, Tribunal Constitucional de Chile, requerimiento por inconstitucionalidad, 4 de agosto de 2000. En: http:// www.tribunalconstitucional.cl/wp/ver.php?id=310 [visitado el 01/09/2011]. 